\title{
Steady State Control Enhancement and Power Flow Analysis of Longitudinal Power Systems Incorporating Interline Power Flow Controller
}

\author{
Olaniyi Isaiah Opeyemi ${ }^{1}$, Adepoju Gafari Abiola ${ }^{1}$, Babatunde Olukotun ${ }^{2}$ \\ ${ }^{1}$ Electronic and Electrical Engineering Department, Ladoke Akintola University of Technology, Ogbomoso, Nigeria \\ ${ }^{2}$ Faculty of Engineering Sciences, University College London and Federal University of Technology, Akure, Nigeria
}

\section{Email address:}

yemiolaniyi01@gmail.com (O. I. Opeyemi), olaniyi_opengr@yahoo.com (O. I. Opeyemi), gaadepoju@lautech.edu.ng (A. G. Abiola), ucembol@ucl.ac.uk (B. Olukotun)

\section{To cite this article:}

Olaniyi Isaiah Opeyemi, Adepoju Gafari Abiola, Babatunde Olukotun. Steady State Control Enhancement and Power Flow Analysis of Longitudinal Power Systems Incorporating Interline Power Flow Controller. American Journal of Electrical Power and Energy Systems. Vol. 6, No. 4, 2017, pp. 27-42. doi: 10.11648/j.epes.20170604.11

Received: April 1, 2017; Accepted: May 12, 2017; Published: July 12, 2017

\begin{abstract}
Transmission lines operating in steady state are prone to several challenges such as; poor steady-state power flow control, active and reactive power loss and voltage limit violations. These challenges can be solved either by the use of Flexible Alternating Current Transmission System (FACTS) controllers such as Interline Power Flow Controller (IPFC) and Generalized Unified Power Flow Controller (GUPFC) or other non-economical means such as building additional generation and transmission facilities. Previous works have incorporated IPFC to solve the challenges in meshed transmission system but has not been applied to solve the challenges of the longitudinal Nigerian transmission system operating in steady state. This work performs power flow analysis with the incorporation of IPFC into the Nigerian 330-kV, 28-bus transmission system to solve its steady state challenges. Steady state power system component model produces a set of algebraic equations while the steady state IPFC model in rectangular form produces another set of algebraic equations for power flow analysis. The sets of equations were solved simultaneously using Newton-Raphson numerical iteration method, due to its fast quadratic convergence and high efficiency. Newton-Raphson power flow algorithm was implemented using MATLAB 8.1.0.604 (version R2013b) and the analysis was performed without and with the incorporation of IPFC data into the Institute of Electrical and Electronic Engineers (IEEE) 14-bus and the Transmission Company of Nigeria (TCN) 330-kV, 28-bus system. The performance evaluation of IPFC was investigated using active and reactive power as performance variables. The incorporation of IPFC rectangular model into the Nigerian 330-kV, 28-Bus TCN and IEEE 14-bus system demonstrated the capability of IPFC to control active and reactive power flow. IPFC typifies effective enhancement and the maximum use of Nigerian 330-kV, 28-Bus TCN and IEEE 14-bus transmission infrastructure for better delivery of electrical power to the end users.
\end{abstract}

Keywords: FACTS, IPFC, IEEE, TCN, Newton-Raphson

\section{Introduction}

Power outages due to transmission lines disruptions are rampant in developing countries. They contribute to the economic down-turn, educational dwarfism, gross dissatisfaction of both artisans and technocrat as a result of low business in-flow, hence; a retrogressive national growth. 1.3 billion, developing country's occupants live without electricity $[1,2]$. Recent global rural growth and urbanization shows that power demand is on a sporadic increase whereas available electrical power system supplies (EPSs) in developing nations are inadequate to meet up with the demand. Sub-Sahara Africa was marked by International Energy Agency (IEA) to have only $32 \%$ electrification, $70 \%$ of which are Nigerian rural indwellers. The aftermath of Nigeria Bureau Statistics (NBS) electricity estimation shows that almost $50 \%$ of the states in Nigeria have more than $50 \%$ of buildings without adequate electricity. Many transmission lines are more loaded than was planned when they were built 
and there exist an uproar matched quest to meet up with the needs of the electricity-starving populace $[2,21]$.

Electricity is indispensable in a seventh most populous ranked nation like Nigeria. Exorbitant cost of constructing more generation and transmission infrastructure as well as limited resources constraint are major barricading challenge for developing countries. Generated power should be effectively transmitted to the distribution network and then to the end users with the bearest minimum losses with improved power output. According to Nigerian Electricity Regulatory Commission (NERC, 2017), in Nigeria, an approximate value of $5300 \mathrm{MW}$ power is not available, and about $3185 \mathrm{MW}$ is not in full operation out of the total installed power generation capacity of $12,522 \mathrm{MW}$. $68 \%$ capacity is not utilized and only $4000 \mathrm{MW}$ is available for transmission and futher distribution. $230 \mathrm{MW}$ power is lost through transmission; $445 \mathrm{MW}$ power is lost through the dilapidated distribution facilities which drastically affect the power that reaches the consumers. Each aspect of the electrical network should be diagnosed separately and solutions proffered to each part for overall national power system efficiency [2, 13, 21]. This research has addressed the challenges of the transmission system with the application of FACTS.

The application of Flexible Alternating Current Transmission System (FACTS) device such as Interline Power Flow Controller (IPFC) is germane to meeting up with the objectives of uninterrupted power supply and a more robust, losses free operational transmission system. IPFC enhances transmission system control, maintains operation at optimum line loading and improves power transmission capability without jeopardizing quality $[2,3]$.

FACTS devices guarantee low system losses and are used as better alternatives to control the flow of heavily loaded lines, shunt compensation, series compensation, phase shifting control, network stability improvements and minimizing economic cost of power transmission. FACTS are fast and are viable power, voltage and impedance controller substitutes for power demand in the transmission infrastructure. In Nigeria, many transmission lines are heavily loaded than were initially planned and the system active and reactive power dissemination is limited as well as poses facility dilapidation which also causes incessant power outages [4]. In the past, attempts have been made to curb power system challenges by the addition of new transmission, generation and distribution facilities but have not significantly met up with the satisfaction of the power consumers. Alternatively, Flexible Alternating Current Transmission Systems (FACTS) controllers ensure the workability of the same objectives with no major alteration to system topology and are preferred by transmission line management companies $[1,9,20]$.

Apart from building compensational sources of energy, such as small hydro-power (SHP) stations or other emerging renewable resources (solar, wind etc.) to meet-up with the satisfactory availability of electricity consumption demand; modern approach epitomizes constructing transmission lines in flexible ways in order to respond to different generation and varying load patterns. The long lengthy transmission lines in the longitudinal network are prone to low voltage profile, high power losses and poor power flow control. Solving the menace as power demand continuously increases is either by building more generating stations (which is involves high capital investment) or expanding the available transmission infrastructure or enhancing the available transmission facility with the incorporation of Flexible Alternating Current Transmission System (FACTS) controllers such as Interline Power Flow Controller (a good option for maximizing the available transmission facility). Enhancing the existing transmission facilities with the incorporation of FACTS controllers to boost power, and minimize losses instead of building new power generating plants is pertinent.

IPFC facilitates the exchange of real and reactive power between the transmission lines and improves the electrical energy delivered to the end users. Power-flow is the computation of voltage magnitude and phase angle at each bus in a power system under balanced three-phase steady-state conditions. As a by-product of this calculation, real and reactive power flows through the transmission lines are computed $[6,8,15]$. The major information obtained from the power-flow study is the magnitude, phase angle of the voltage at each bus, the real and reactive power flowing in each line at an instant. [6, 10, 16].

This study considers power flow solution in steady state and focuses on the 28 -bus Nigeria $330 \mathrm{kV}$ grid system. Owing to its fast convergence and small number of iteration, high efficiency, and wide practical applications, Newton-Raphson among other iterative solution methods of non-linear algebraic equations has been adopted. The power injection model of IPFC has been formulated in rectangular co-ordinate, with simulations carried out through a developed power flow algorithm which shows the application of FACTS devices and their steady state enhancement capability.

Classification of FACTS Controllers

The Institute of Electrical Electronic Engineers (IEEE) defined FACTS as "Power electronic based system and other static equipment that provide control of one or more $\mathrm{AC}$ transmission system parameters to enhance controllability and increase power transfer capability." FACTS controllers can be classified based on the connectivity of their controller [1]. Figure 1a shows the classification of FACTS controllers based on how power electronic devices are used for the control i.e (a) Variable impedance type and (b) Voltage Source Converter (VSC) - based.

The benefits of employing FACTS are many: Reduction of system losses, improvement of dynamic and transient-stability, control of real and reactive power as per system requirement, and security improvement, flexibility in operation, less active and reactive power loss, power profile and power quality improvement optimal system operation, improving line capacity and loading ability of the system, increasing power flow capability through the transmission line, and voltage regulation improvement, system efficiency, voltage margin improvement. FACTS controllers play a leading role in the efficient control of the line power flow and power system voltage profile improvement. FACTS controllers can be used 
to increase the reliability and efficiency of transmission and distribution systems. Several generations of these developed control devices exist; the first generation centers on the conventional Thyristor switched capacitors and reactors, and tap changing transformers, while, the second generation uses the GTO Thyristor switched converters as voltage regulator $[7$, $9,11,18]$.

Figure $1 \mathrm{~b}$ shows the classification of FACTS based on evolving genealogy. The first generation has resulted in the SVC, and TCSC. The second generation encompasses STATCOM and SSSC. UPFC belongs to third generation while IPFC, and GUPFC are grouped under fourth generation. These groups of FACTS controllers have distinctly different operating and performance characteristics and IPFC is a burgeoning member of the FACTS family.

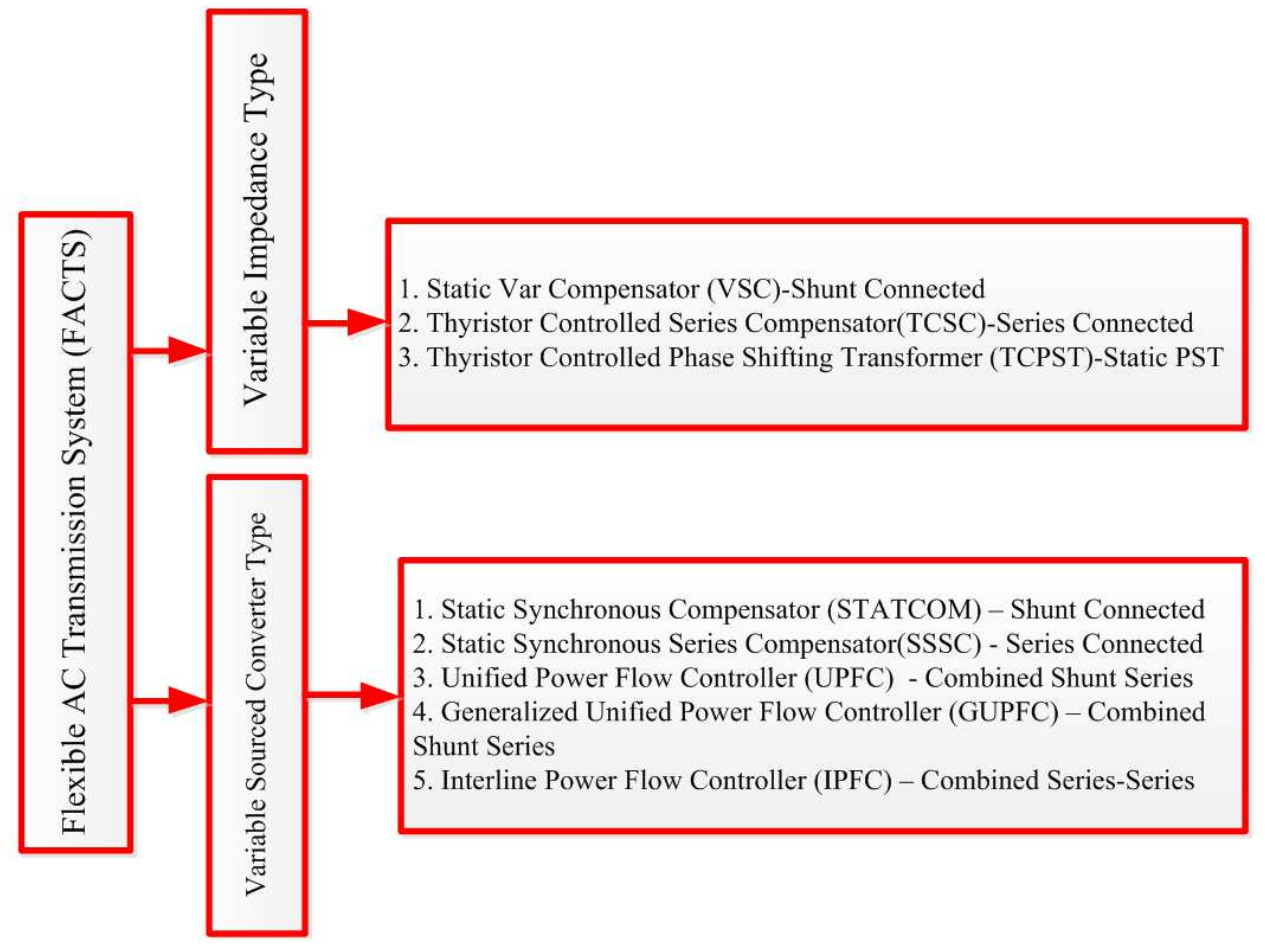

Figure 1a. Classification of FACTS Based on Type.

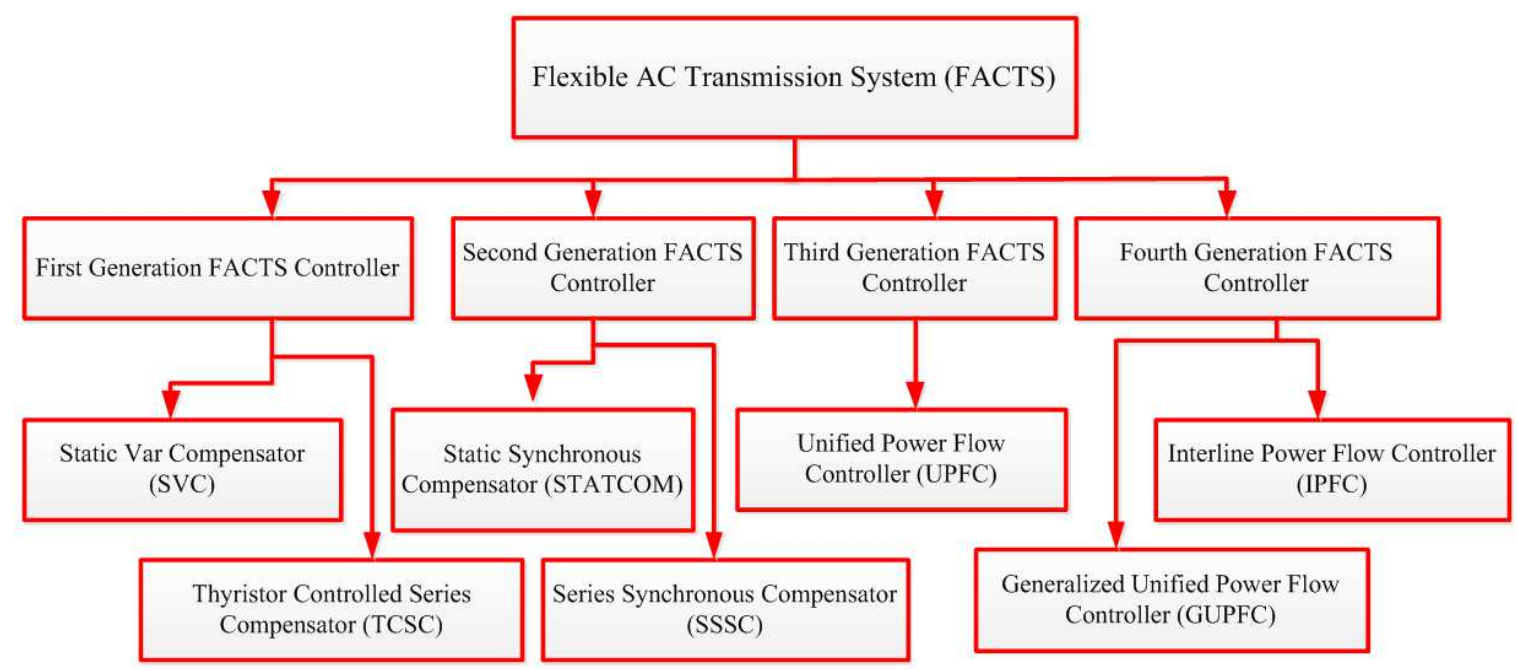

Figure 1b. Classification of FACTS Based on Generation.

The power flow over a transmission line depends mainly on three important parameters, namely voltage magnitude of the buses, impedance of the transmission line $(Z)$ and phase angle between buses. The FACTS devices control one or more parameters to improve system performance through appropriate placement and coordination of multiple FACTS controllers $[4,5,11]$. It is found in large-scale emerging power system networks to achieve significant improvements in operating parameters of the power systems such as small signal stability, transient stability, damping of power system oscillations, security of the power system, less active power loss, voltage profile, congestion management, quality of the 
power system, efficiency of power system operations, power transfer capability through the lines, dynamic performances of power systems, and the loadability of the power system network. FACTS devices are fabricated using solid state controllers; their response is fast and accurate [19, 20].

The Interline Power Flow Controller (IPFC) is a combination of two or more independently controllable static synchronous series compensators (SSSC) which are solid-state voltage source converters and inject an almost sinusoidal voltage at variable magnitude and couples via a Common DC link. [15, 17]. Conventionally, series capacitive compensation weather fixed, Thyristor controlled or SSSC based, is employed to increase the transmittable real power over a given line and to balance the loading of a normally encountered multi-line transmission system. They are controlled to provide a capability to directly transfer independent real power between the compensated lines while maintaining the desired distribution of reactive flow between the lines.

The operation of IPFC can be considered as an extension of Static Synchronous Series Condenser (SSSC), where the series injected voltage must always be in quadrature with the line current to ensure zero real power at the common dc link. This implies that only the magnitude of injected voltage can be controlled. In case of IPFC, there will be at least two series compensated lines coupled to the dc buses of the VSCs. Therefore, both the injected voltage magnitude and phase angle can be controlled [7, 9, 12, 14].

\section{Methodology}

\subsection{Mathematical Modeling of IPFC in Rectangular Form}

Figure 2 is a one line representation of IPFC containing n-converters. It typifies that the active power exchanged between Voltage Source Converter one ( $\left.\mathrm{VSC}_{1}\right)$ to the next is predefined and therefore only its series reactive compensation freely varies to control the active power flow or the reactive power flow of its series connected transmission line.

Mathematical power injection model of IPFC has been derived. All buses are infinite and the two systems are AC sources. Interline power flow controller neither absorbs nor injects active power with respect to the ac system, the active power exchange between the converters via the common dc link is zero.

A Circuit of a two Converter Interline Power Flow Controller is shown in Figure 3 while the equivalent diagram of the IPFC model for power injection mathematical modeling is shown in Figure 4. This model enunciates the steady-state enhancement and control capacity of the IPFC on the power system in the steady state when it is incorporated in the power flow model. In the steady state analysis of power systems, the voltage sourced converters VSC is a synchronous voltage source injecting sinusoidal voltage with controllable magnitude and angle.

In Figure 4, an equivalent circuit of IPFC with two controllable series injected voltage source is presented, with power entering and leaving each bus according to the directional arrows. In rectangular form the series voltage equation can be written as;

$$
V_{s e_{\text {in }}}=e_{\text {se in }}+j f_{\text {se in }}
$$

Where: $\mathrm{n}=\mathrm{j}, \mathrm{k}$ (Bus $\mathrm{j}$ or bus $\mathrm{k}$ )

$V s e_{i n}$ is the complex controllable series injected voltage source. $Z s e_{i n}$ (where $\mathrm{n}=\mathrm{j}, \mathrm{k}$ ) is the series coupling transformer impedance.

The current source is

$$
\begin{gathered}
I_{s e_{i n}}=-j b_{s e_{i n}} V_{s e_{i n}} \\
\therefore S_{i n_{j, i}}=\sum_{n=j, k} V_{i}\left(-I_{s e_{i n}}\right)^{*} \\
S_{i n_{j, i}}=\sum_{n=j, k} V_{i}\left(j b_{s e_{i n}} V_{s e_{i n}}\right)^{*}
\end{gathered}
$$

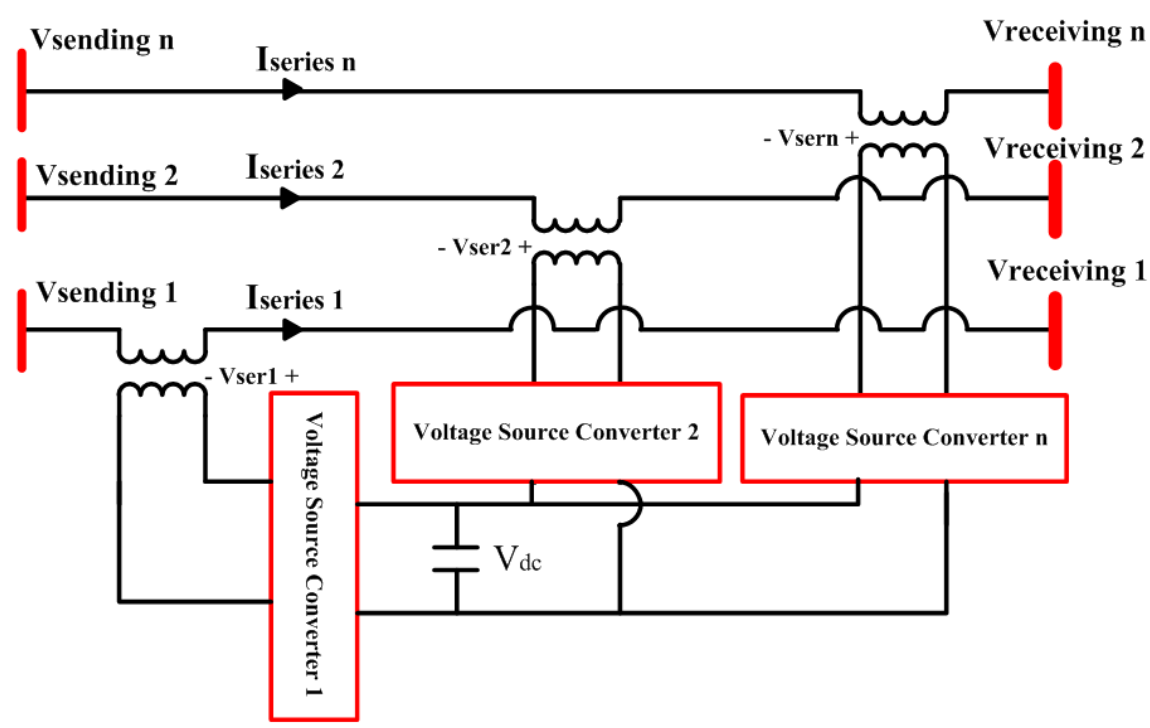

Figure 2. Configuration of Interline Power Flow Controllers Containing n-Converter. 


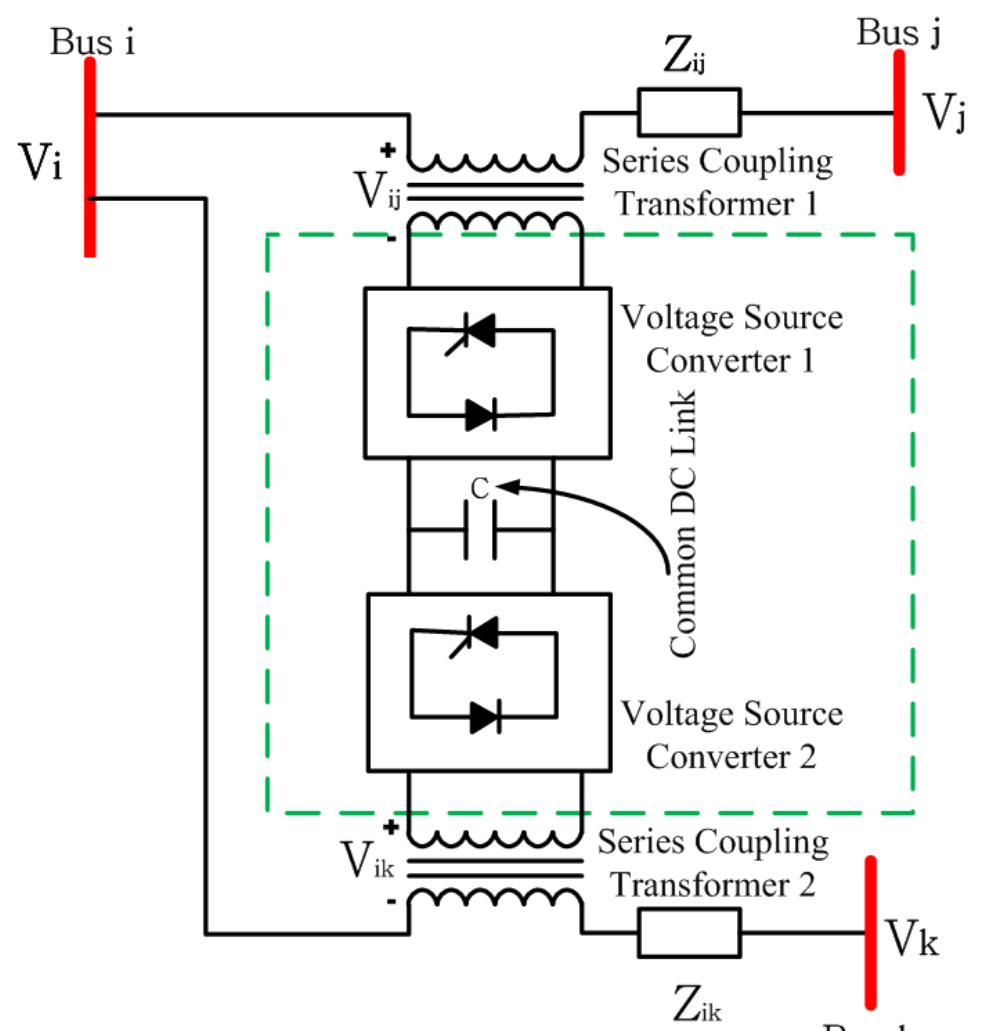

Bus k

Figure 3. Circuit of a two Converter Interline Power Flow Controller.

Complex power flow equations of the IPFC branches modeled in rectangular form are;

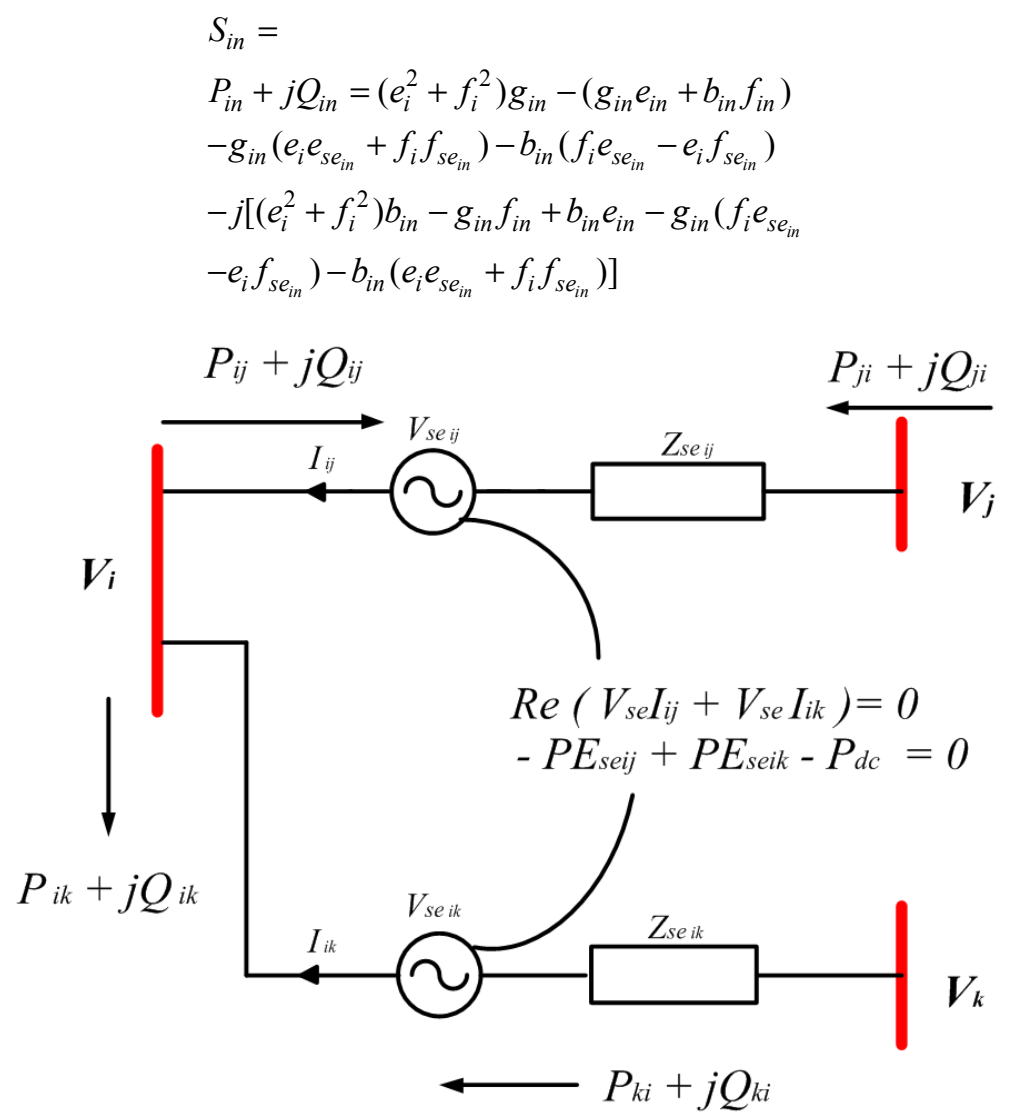

Figure 4. Equivalent Circuit of two Converter Interline Power Flow Controller. 
Group together the like terms, equation (5) becomes

$$
\begin{aligned}
& S_{i n}= \\
& \left(e_{i}^{2}+f_{i}^{2}\right)\left(g_{i n}-b_{i n}\right)-g_{i n}\left(e_{i n}+f_{i n}\right) \\
& +b_{i n}\left(e_{i n}-f_{i n}\right)-g_{i n}\left(e_{i} e_{s e_{i n}}+f_{i} f_{s e_{i n}}\right. \\
& \left.+e_{s e_{i n}} f_{i}-e_{i} f_{s e_{i n}}\right)+b_{i n}\left(f_{i} e_{s e_{i n}}-e_{i} f_{s e_{i n}}\right. \\
& \left.+e_{i} e_{s e_{i n}}+f_{i} f_{s e_{i n}}\right)
\end{aligned}
$$

Where:

$$
g_{i n}=\operatorname{Re}\left(\frac{1}{Z_{s e}}\right) ; b_{i n}=\operatorname{Im}\left(\frac{1}{Z_{s e}}\right) \text {, }
$$

(Where $\mathrm{n}=\mathrm{j}, \mathrm{k}$ ) are the active and reactive power flows of two IPFC branches leaving bus $i$.

The following equations represent the Active and Reactive power injections at each bus of the system.

$$
\begin{aligned}
& P_{i n}=\operatorname{Re}\left(S_{i n}\right)=\left(e_{i}^{2}+f_{i}^{2}\right) g_{\text {in }} \\
& -\left(g_{i n} e_{i n}+b_{i n} f_{i n}\right)-g_{i n}\left(e_{i} e_{s e_{i n}}\right. \\
& \left.+f_{i} f_{s e_{i n}}\right)-b_{i n}\left(f_{i} e_{s e_{i n}}-e_{i} f_{s e_{i n}}\right) \\
& Q_{i n}=\operatorname{Im}\left(S_{i n}\right)=-\left(e_{i}^{2}+f_{i}^{2}\right) b_{i n} \\
& \left.-g_{i n} f_{i n}+b_{i n} e_{i n}\right)-g_{i n}\left(f_{i} e_{s e_{i n}}\right. \\
& \left.+e_{i} f_{s e_{i n}}\right)-b_{i n}\left(e_{i} e_{s e_{i n}}-f_{i} f_{s e_{i n}}\right)
\end{aligned}
$$

For $\mathrm{n}=\mathrm{j}$;

$$
\begin{aligned}
& P_{i j}=\operatorname{Re}\left(S_{i j}\right)= \\
& \left(e_{i}^{2}+f_{i}^{2}\right) g_{i j}-\left(g_{i j} e_{i j}+b_{i j} f_{i j}\right) \\
& -g_{i j}\left(e_{i} e_{s e_{i j}}+f_{i} f_{s e_{i j}}\right)-b_{i j}\left(f_{i} e_{s e_{i j}}\right. \\
& \left.-e_{i} f_{s e_{i j}}\right) \\
& Q_{i j}=\operatorname{Im}\left(S_{i j}\right)=-\left(e_{i}^{2}+f_{i}^{2}\right) b_{i j} \\
& \left.-g_{i j} f_{i j}+b_{i j} e_{i j}\right)-g_{i j}\left(f_{i} e_{s e_{i j}}+\right. \\
& \left.e_{i} f_{s e_{i j}}\right)-b_{i j}\left(e_{i} e_{s e_{i j}}-f_{i} f_{s e_{i j}}\right)
\end{aligned}
$$

For $\mathrm{n}=\mathrm{k}$

$$
\begin{gathered}
P_{i k}=\operatorname{Re}\left(S_{i k}\right)=\left(e_{i}^{2}+f_{i}^{2}\right) g_{i k} \\
-\left(g_{i k} e_{i k}+b_{i k} f_{i k}\right)-g_{i k}\left(e_{i} e_{s e_{i k}}\right. \\
\left.+f_{i} f_{s e_{i k}}\right)-b_{i k}\left(f_{i} e_{s e_{i k}}-e_{i} f_{s e_{i k}}\right) \\
Q_{i k}=\operatorname{Im}\left(S_{i k}\right)=-\left(e_{i}^{2}+f_{i}^{2}\right) b_{i k} \\
\left.-g_{i k} e_{i k}+b_{i k} f_{i k}\right)-g_{i k}\left(e_{i} e_{s e_{i k}}\right. \\
\left.+f_{i} f_{s e_{i k}}\right)-b_{i k}\left(f_{i} e_{s e_{i k}} e_{i} f_{s e_{i k}}\right)
\end{gathered}
$$

For the series IPFC branch, the active and reactive power flows for branch leaving bus $\mathrm{i}$ to bus $\mathrm{n}$ (where $\mathrm{n}=\mathrm{j}, \mathrm{k}$ ) are;

$$
\begin{aligned}
& P_{n i}=\operatorname{Re}\left(S_{n i}\right)=-\left(e_{i}^{2}+f_{i}^{2}\right) b_{n i} \\
& -\left(g_{n i} f_{n i}+b_{n i} e_{n i}\right)-g_{n i}\left(f_{i} e_{s e_{n i}}\right. \\
& \left.+e_{i} f_{s e_{n i}}\right)+b_{n i}\left(e_{i} e_{s e_{n i}}+f_{i} f_{s e_{n i}}\right) \\
& Q_{n i}=\operatorname{Im}\left(S_{n i}\right)=-\left(e_{i}^{2}+f_{i}^{2}\right) b_{n i} \\
& \left.-g_{n i} f_{n i}+b_{n i} e_{n i}\right)-g_{n i}\left(f_{i} e_{s e_{i n}}\right. \\
& \left.+e_{i} f_{s e_{i n}}\right)-b_{i n}\left(e_{i} e_{s e_{i n}}-f_{i} f_{s e_{i n}}\right)
\end{aligned}
$$

For $\mathrm{n}=\mathrm{j}$

$$
\begin{gathered}
P_{j i}=\operatorname{Re}\left(S_{j i}\right)=-\left(e_{i}^{2}+f_{i}^{2}\right) b_{j i} \\
-\left(g_{j i} f_{j i}+b_{j i} e_{j i}\right)-g_{j i}\left(f_{i} e_{s e_{j i}}\right. \\
\left.+e_{i} f_{s e_{j i}}\right)+b_{j i}\left(e_{i} e_{s e_{j i}}+f_{i} f_{s e_{j i}}\right) \\
Q_{j i}=\operatorname{Im}\left(S_{j i}\right)=-\left(e_{i}^{2}+f_{i}^{2}\right) b_{j i} \\
\left.-g_{j i} f_{j i}+b_{j i} e_{j i}\right)-g_{j i}\left(f_{i} e_{s e_{j i}}\right. \\
\left.+e_{i} f_{s e_{j i}}\right)-b_{j i}\left(e_{i} e_{s e_{j i}}-f_{i} f_{s e_{j i}}\right)
\end{gathered}
$$

For $\mathrm{n}=\mathrm{k}$

$$
\begin{aligned}
& P_{k i}=\operatorname{Re}\left(S_{k i}\right)=-\left(e_{i}^{2}+f_{i}^{2}\right) b_{k i} \\
& -\left(g_{k i} f_{k i}+b_{k i} e_{k i}\right)-g_{k i}\left(f_{i} e_{s e_{k i}}\right. \\
& \left.+e_{i} f_{s e_{k i}}\right)+b_{k i}\left(e_{i} e_{s e_{k i}}+f_{i} f_{s e_{k i}}\right) \\
& Q_{k i}=\operatorname{Im}\left(S_{k i}\right)=-\left(e_{i}^{2}+f_{i}^{2}\right) b_{k i} \\
& \left.-g_{k i} f_{k i}+b_{k i} e_{k i}\right)-g_{k i}\left(f_{i} e_{s e_{k i}}\right. \\
& \left.+e_{i} f_{s e_{k i}}\right)-b_{k i}\left(e_{i} e_{s e_{k i}}-f_{i} f_{s e_{k i}}\right)
\end{aligned}
$$

IPFC neither absorbs nor injects active power with respect to the ac system, so the active power exchange between the converters via the dc link is zero, i.e

$$
\operatorname{Re}\left(V_{s e_{i j}} I_{s e_{j i}}^{*}+V_{s e_{i k}} I_{k i}^{*}\right)=0 \text { OR }-P E_{s e_{i j}}-P E_{s e_{i k}}-P_{d c}=0
$$

Where the superscript * denotes the conjugate of a complex number and $\mathrm{PE}$ is the power exchange between the lines, $\mathrm{P}_{\mathrm{dc}}$ is the power developed as a result of the DC link. If the resistances of series transformers are neglected, the equation can be written as:

$$
\sum_{m=i, j, k} P_{i n_{j, m}}=0
$$

With invoked active and reactive constraints of 


$$
\begin{gathered}
\Delta P_{n i}=P_{n i}-P_{n i}^{s p e c}=0 \\
\Delta Q_{n i}=Q_{n i}-Q_{n i}^{s p e c}=0
\end{gathered}
$$

Where $n=j, k, P_{n i}^{s p e c}, Q_{n i}^{s p e c}$ are the specified active and reactive power flow control references respectively,

And the IPFC power mismatch equations are;

$$
\begin{gathered}
\Delta P_{m}=P_{g m}-P_{d m}-P_{\text {line }, m}=0 \\
\Delta Q_{m}=Q_{g m}-Q_{d m}-Q_{\text {line }, m}=0
\end{gathered}
$$

where; $P_{g m}$ and $Q_{g m}(m=i, j$ and $k)$ are the real and reactive power generation entering bus m, $P_{d m}$ and $Q_{d m}$ are load active and reactive powers leaving bus m. $P$ line, $m$ and $Q$ line, $m$ are sum of real and reactive transmitted powers at the bus $m=i, j$ and $k$.

Equation (16) to (21) represent the IPFC equations, Equation (22) to (23) denotes the constraints equation invoked on the IPFC system and Equation (24) to (25) represent the power mismatch equations.

\subsection{Incorporation of IPFC Model in Newton Load Flow with Jacobian Matrix Elements}

Real power is exchanged among the series converters via the common DC link while the sum of the real power exchange equals zero for an equivalent circuit of IPFC with two controllable series injected voltage sources.

In figure 4 , the IPFC is located between nodes $\mathrm{i}, \mathrm{j}$ and $\mathrm{k}$ in the secondary converter $i-k$ has one control degree of freedom while primary series converter $i-j$ has two controls degrees of freedom. Another control degree of freedom of the converter is used to balance the active power exchange between the two series converters [1, 7] [15]. Having combined the power mismatch equations (24) and (25) and the control equations (i.e. equations (16) to (21)). The Newton power flow matrix is;

$$
[-\Delta G]=[J][\Delta U]
$$

Where;

$\Delta U$ is the incremental vector of state variables and $\Delta U=\left[\begin{array}{ll}U_{1} & U_{2}\end{array}\right]^{T}$

$$
\begin{aligned}
\Delta U_{1} & =\left[\begin{array}{llllll}
\Delta e_{i} & \Delta f_{i} & \Delta e_{j} & \Delta f_{j} & \Delta e_{k} & \Delta f_{k}
\end{array}\right]^{T} \text { and } \\
\Delta e_{i k} & =\left[\begin{array}{llll}
\Delta e_{s e_{i j}} & \Delta f_{i j} & \Delta e_{i k} & \Delta f_{i k}
\end{array}\right]^{T} \text { for the incremental }
\end{aligned}
$$
vector of the state variable

$\Delta G$ is the bus power mismatch and IPFC control mismatch vector and $\Delta G=\left[\begin{array}{ll}G_{1} & G_{2}\end{array}\right]^{T}$

$$
\Delta G_{1}=\left[\begin{array}{llllll}
\Delta P_{i} & \Delta Q_{i} & \Delta P_{j} & \Delta Q_{j} & \Delta P_{k} & \Delta Q_{k}
\end{array}\right]^{T} \text { for bus }
$$

power mismatch vector

$$
\Delta G_{2}=\left[\begin{array}{llll}
P_{j i}-P_{j i}^{s p e c} & Q_{j i}-Q_{j i}^{s p e c} & P_{k i}-P_{k i}^{s p e c} & P E x
\end{array}\right]^{T}
$$

Operating control mismatch vector of the IPFC.

$$
J=\frac{\partial G}{\partial U} \text { System Jacobian Matrix }
$$

\subsection{Power Balance Equations with IPFC}

The IPFC power injection model can be incorporated into Newton-Raphson power flow algorithm by the addition of power injection to the corresponding power mismatch equations. The power balance equations can be expressed as;

$$
\begin{aligned}
& \Delta P_{i}=\Delta P_{i}^{t}+P_{i n_{j, i}} \\
& \Delta Q_{i}=\Delta Q_{i}^{t}+Q_{i n_{j, i}} \\
& \Delta P_{n}=\Delta P_{n}^{t}+P_{i n_{j, n}} \\
& \Delta Q_{n}=\Delta Q_{n}^{t}+Q_{i n_{j, n}}
\end{aligned}
$$

Where the superscript ' $t$ ' in all the equations denote the power mismatch without IPFC and $\mathrm{n}=\mathrm{j}, \mathrm{k}$

Having obtained line, bus, generator and load data for this research work were obtained from the Transmission Company Nigeria (TCN).

\subsection{Simulation of Newton-Raphson Algorithms with the Incorporation of IPFC}

Non-linear algebraic power flow equations were solved using MATLAB 8.1.0.604 (version R2013b) without and with the incorporation of IPFC. The simulation was carried out according to the algorithm below;

1) Read the $330 \mathrm{kV} 28$-bus power flow data (or IEEE 14 bus data) and IPFC data.

2) Take flat voltage profile start (i.e. all voltage angles are initially set to zero and all voltage magnitudes are set to 1.0 p.u) and set iteration count $\mathrm{m}=0$

3) Solve the power balance equations using the recent voltage angle and magnitude values

4) Compute active and reactive power mismatch.

5) Compute the Jacobian matrix using Newton-Raphson (NR) method equations.

6) Modify power mismatch and Jacobin using IPFC mathematical model equations.

7) If the maximal absolute mismatch is less than tolerance, display results as output. Otherwise, go to step 8.

8) solve the Newton-Raphson equations; obtain the voltage angle and magnitude correction vector

9) Update the NR solution

10) Set $m=m+1$, initialize back to step 3

Figure 5 denotes the pictorial representation of the power flow solution method without and with the incorporation of IPFC FACTS device. 


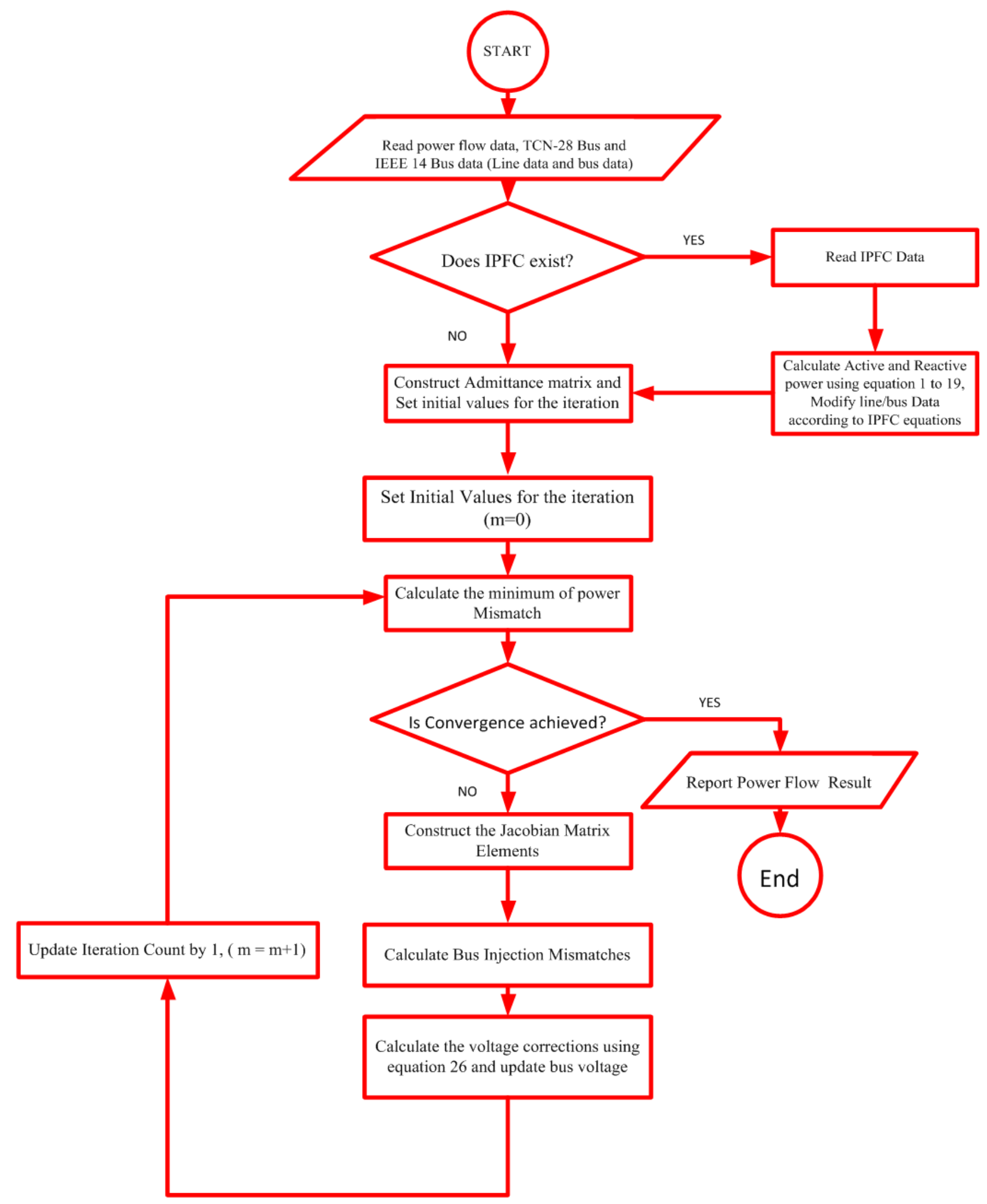

Figure 5. Flow chat for the Power flow without and with IPFC.

\section{Result and Discussion}

The Nigerian 28-bus system is made up of 9 voltage controlled buses (slack bus inclusive) and 19 load buses. The placement of IPFC is in-between buses with only one or no generator bus (a close-by generator source to a bus constitute 
incessant fault for power flow analysis) and lines with inadequate real and reactive power flow. Steady state operation of the Nigerian system identified the lines between bus 12-14 and 13-14 to have insufficient active and reactive power values. These consequently results to low voltage supply at these buses. IEEE-14 bus data shows the same deficiency between lines of buses 1, 2 and 5. IPFC rectangular model enhanced the steady state control of both systems and power flow results show significant active and reactive power improvement. Power flow equations are generally quadratic in nature but the rectangular power flow model is a more simplified algorithm for greater accuracy using Newton-Raphson [13, 21].

This section discusses two test cases considered and corresponding results are presented. Test case one discusses 14-bus power flow result without IPFC; and 14-bus power flow results with the incorporation of IPFC. Case two considers 28-bus power flow result without IPFC and 28-bus power flow results with the incorporation of IPFC. Bus 1 served as slack bus in all cases. The system base MVA value is 100 and the tolerance value of $10 \times 10^{-12}$ p.u was used for computation.

\subsection{Test Case 1: 14-Bus Power Flow Results Without and with IPFC}

Figure 6 shows the IEEE-14 bus system with IPFC installed in between the lines connecting bus 1,2 and 5. The effect of Vse is investigated when varied between four values; $(0.025$ p.u, 0.05 p.u, 0.075 p.u and 0.1 p.u). The angle $\theta$ se is varied $\pi\left(-180^{\circ}\right)$ to $+\pi\left(+180^{\circ}\right)$. Figure 7 and 8 shows the 14-Bus active and reactive power flow results. Between Bus 1 to 5, Active power was 75.509 MW without IPFC and 76.442 MW having installed IPFC (i.e. Active power increased by 0.933 MW. Reactive power without IPFC was 3.961 MVar and 5.561 MVar having installed IPFC (i.e. Reactive power increased by 1.60 MVar. Between Bus 2 and 5, Active power was $41.533 \mathrm{MW}$ without IPFC and $45.117 \mathrm{MW}$ with the incorporation of IPFC (i.e. Active power increased by 3.584 MW. Similarly, Reactive power without IPFC was 1.302 MVar and 2.311 MVar with the incorporation of IPFC (i.e. Reactive power increased by 1.009 Mvar) without exceeding the system capacity limit within the IPFC control capacity.

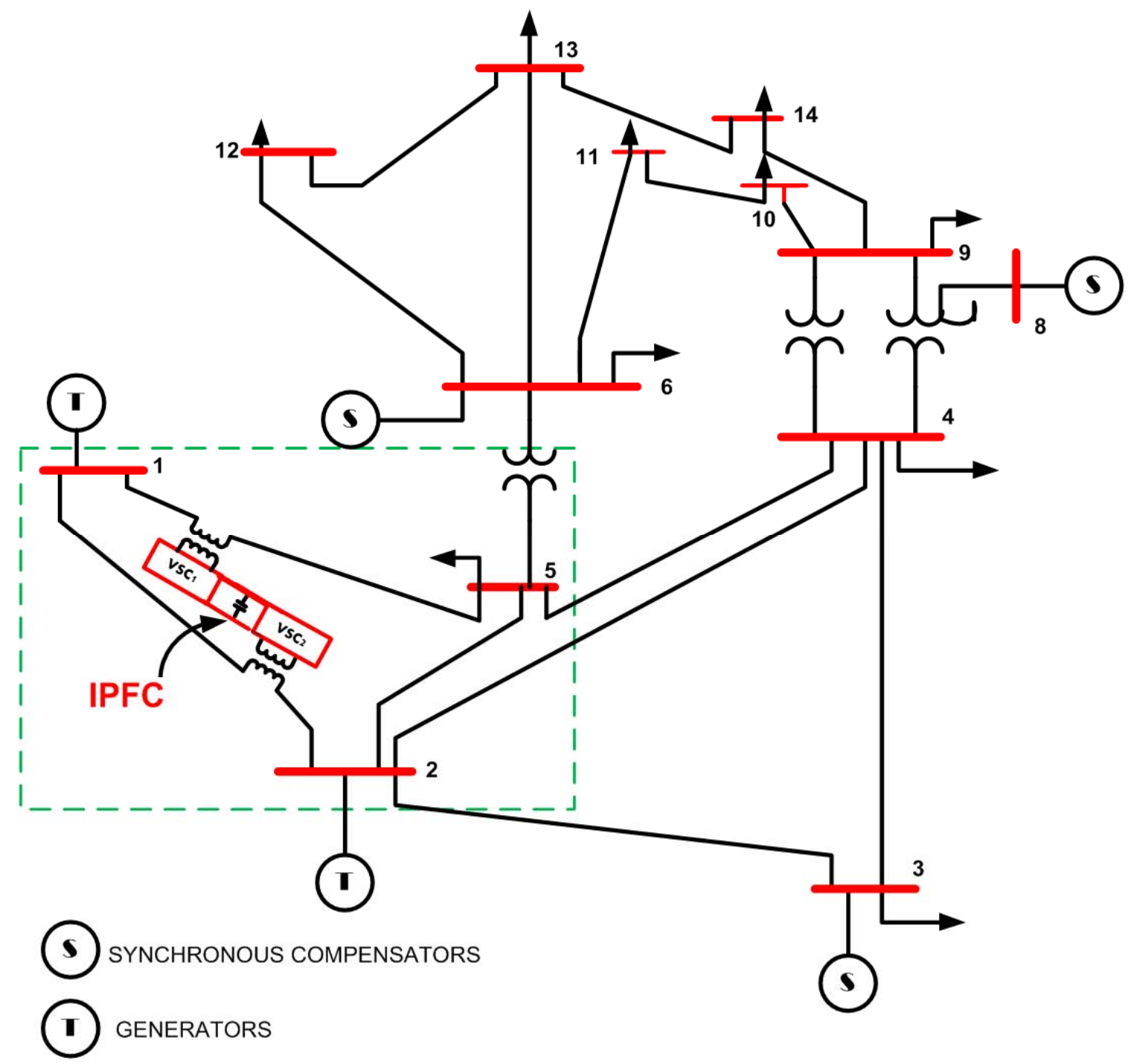

Figure 6. IEEE-14 Bus System with IPFC Installed. 


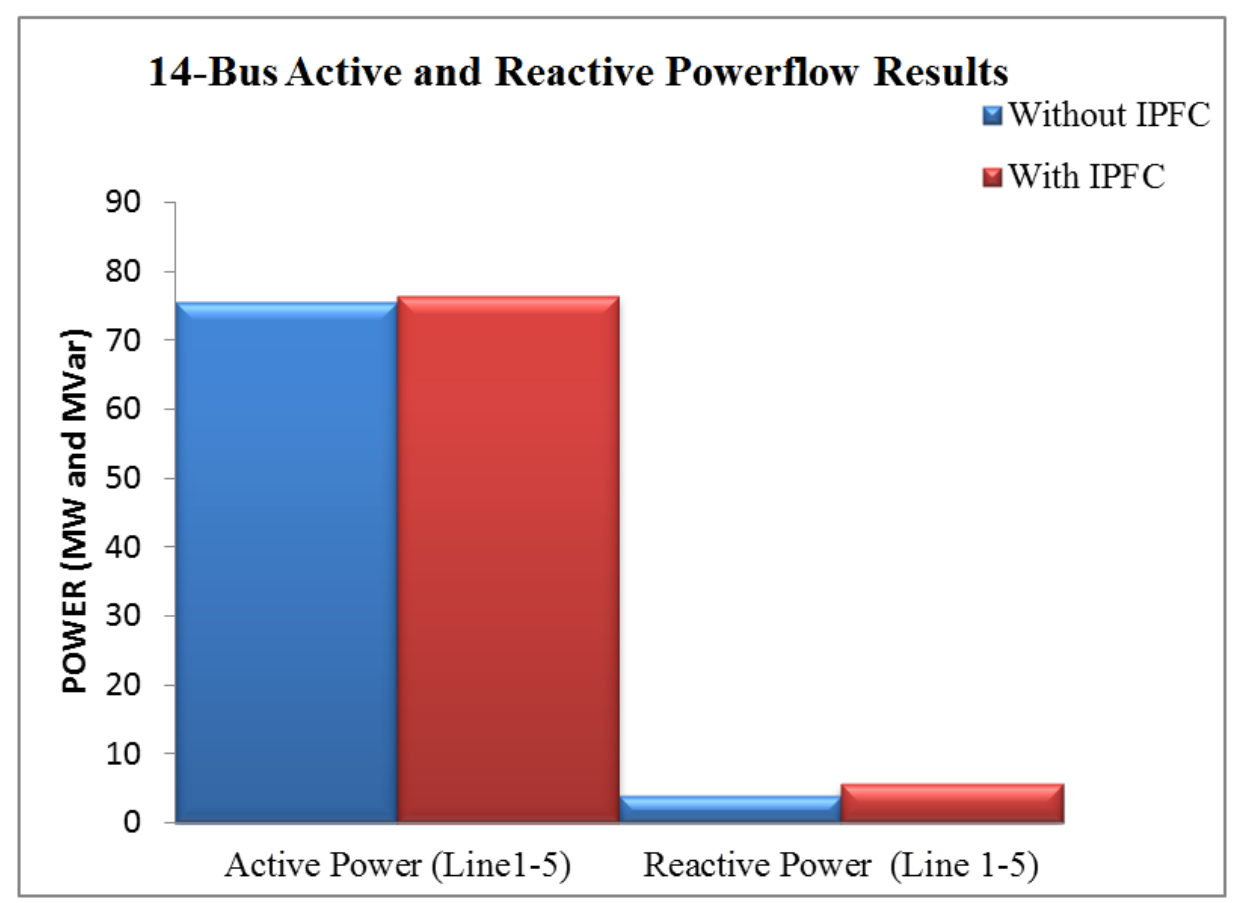

Figure 7. 14-Buses Active and Reactive Power flow Results (Line connecting bus 1-5).

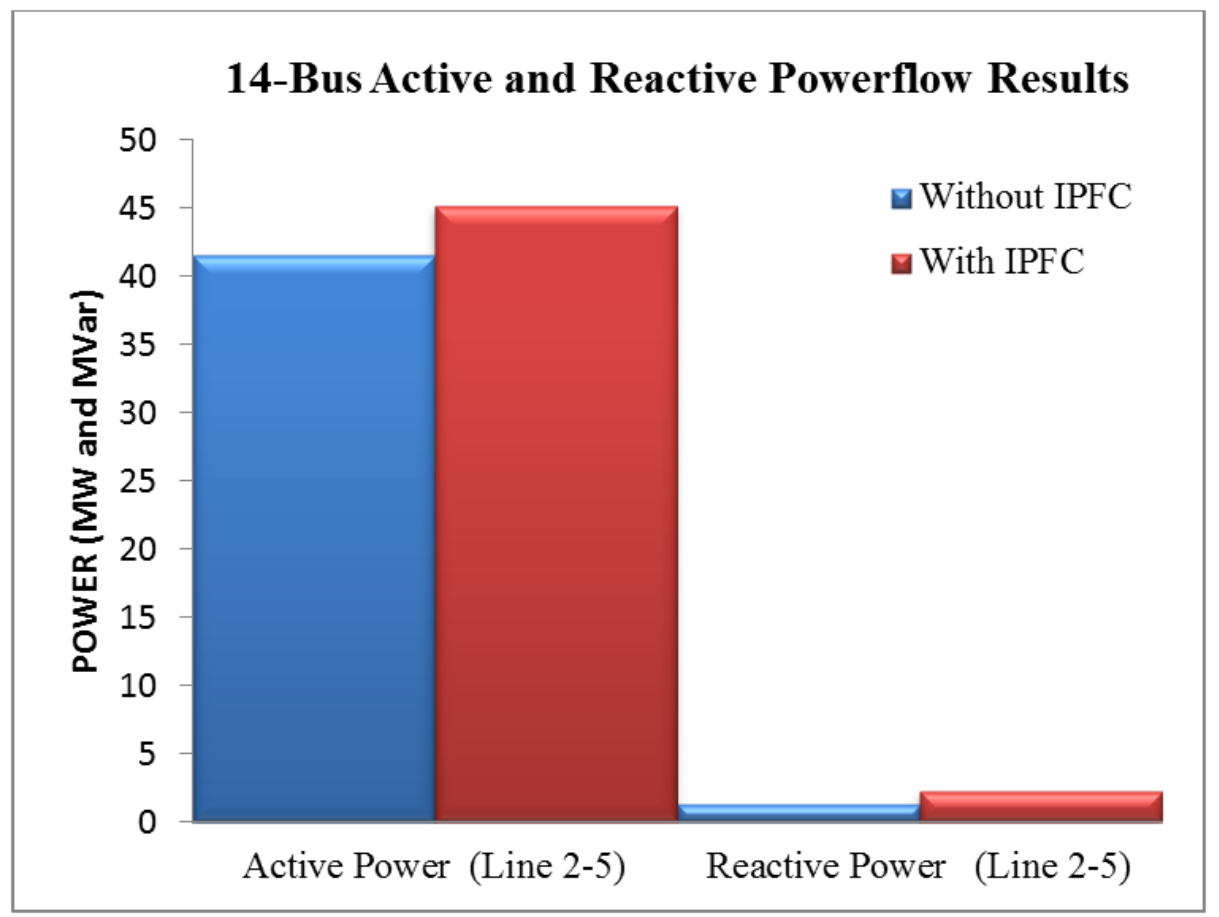

Figure 8. 14-Bus Active and Reactive Power flow Results (Line connecting bus 2-5).

Figure 9 to 12 shows the graphical behavior of active and reactive power at selected buses where IPFC has been installed (Buses 1-5 and 2-5) while varying Vse and $\theta$ se control parameters. As Vse increases from 0.025 p.u at an interval of 0.025 to $0.1 \mathrm{p}$.u for different values of $\theta$ se (ranging from $-180^{\circ}$ to $+180^{\circ}$ ), the active and reactive power flow in both lines increased having incorporated IPFC.

Table 1 shows the effect of keeping Series voltage and angle constant on the active power, reactive power and line flows. It typifies an improvement in the active and reactive power compared to the previously considered cases of the 14-bus power system.

Table 1. IEEE 14-Bus and Line Flows with IPFC at Series Voltage and Angle of $V_{s e} \angle \theta_{s e}=0.085 \angle 115^{\circ}$.

\begin{tabular}{llll}
\hline \multicolumn{4}{l}{ Active and Reactive Power Line Flows } \\
\hline Bus & \multicolumn{3}{l}{ With IPFC } \\
\hline From & To & MW & MVar \\
\hline 1 & 5 & 81.635 & 4.215 \\
2 & 5 & 49.261 & 1.594 \\
\hline
\end{tabular}




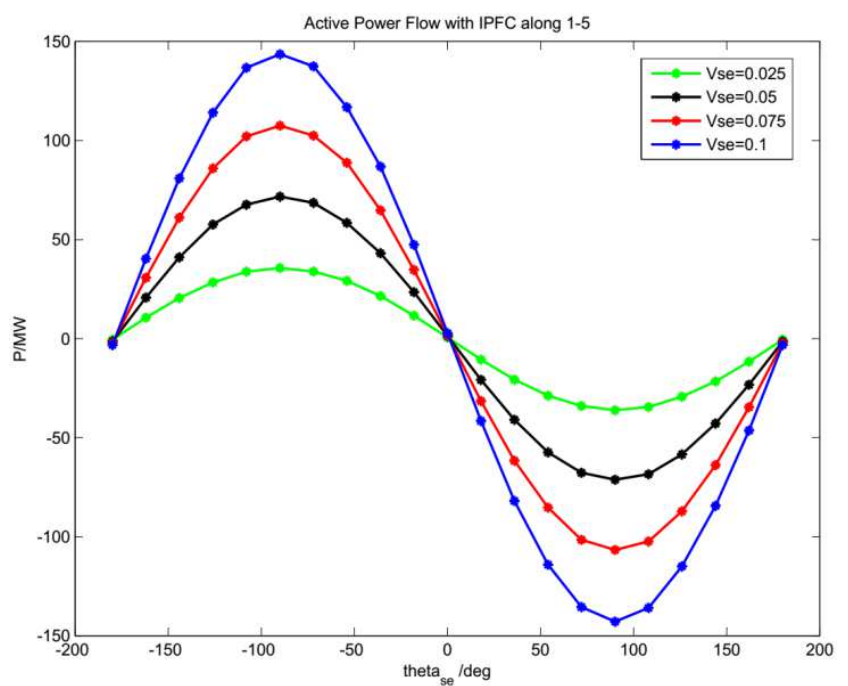

Figure 9. Active power flow with IPFC in the line connecting bus 1 to bus 5 at various values of Vse.

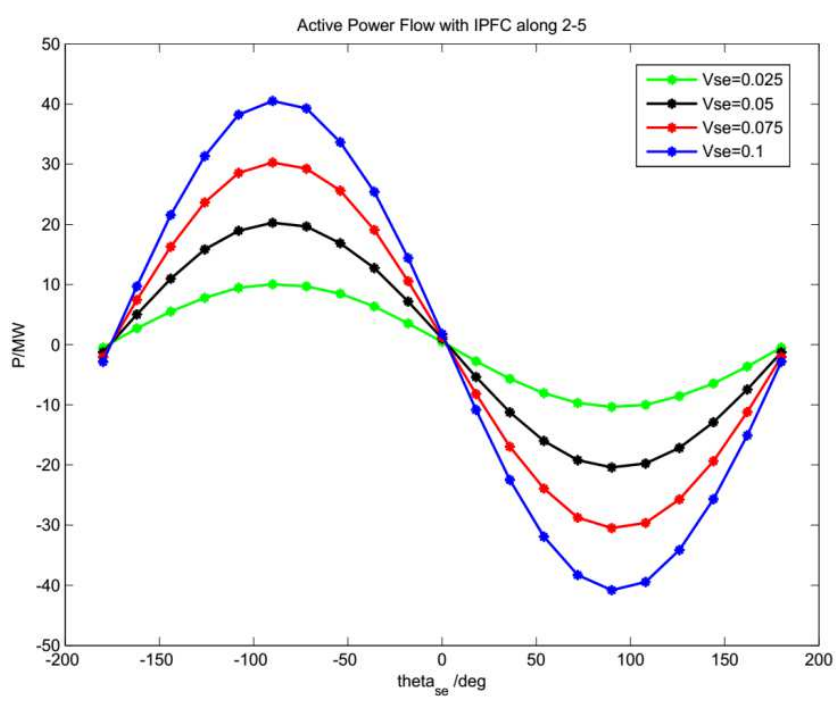

Figure 10. Active power flow with IPFC in the line connecting bus 2 to bus 5 at various values of $V$ se.

Table 2. 28-Bus Power flow Results without IPFC.

\begin{tabular}{llll}
\hline BUS & BUS & VOLTAGE & VOLTAGE \\
\hline NUMBER & TYPE & MAGNITUDE (P.U.) & ANGLE (Deg) \\
\hline 1 & Swing & 1.050 & 0.000 \\
2 & PV & 1.050 & 11.840 \\
3 & PQ & 1.045 & -0.284 \\
4 & PQ & 1.019 & 0.641 \\
5 & PQ & 1.026 & 1.065 \\
6 & PQ & 1.062 & 5.964 \\
7 & PQ & 1.046 & 10.274 \\
8 & PQ & 1.041 & 6.322 \\
9 & PQ & 0.990 & 1.971 \\
10 & PQ & 1.031 & 7.598 \\
11 & PV & 1.050 & 10.223 \\
12 & PQ & 1.038 & 9.568 \\
13 & PQ & 0.977 & 2.442 \\
\hline
\end{tabular}

\begin{tabular}{llll}
\hline BUS & BUS & VOLTAGE & VOLTAGE \\
\hline NUMBER & TYPE & MAGNITUDE (P.U.) & ANGLE (Deg) \\
\hline 14 & PQ & 0.994 & 3.766 \\
15 & PQ & 1.065 & 13.608 \\
16 & PQ & 0.994 & 3.685 \\
17 & PQ & 1.050 & 13.292 \\
18 & PV & 1.050 & 13.555 \\
19 & PQ & 1.051 & 9.797 \\
20 & PQ & 1.040 & 5.939 \\
21 & PV & 1.050 & 16.460 \\
22 & PQ & 1.010 & 1.968 \\
23 & PV & 1.050 & 8.110 \\
24 & PV & 1.050 & 7.870 \\
25 & PQ & 1.049 & 13.631 \\
26 & PQ & 1.029 & 6.032 \\
27 & PV & 1.050 & 25.280 \\
28 & PV & 1.050 & 3.274 \\
\hline
\end{tabular}

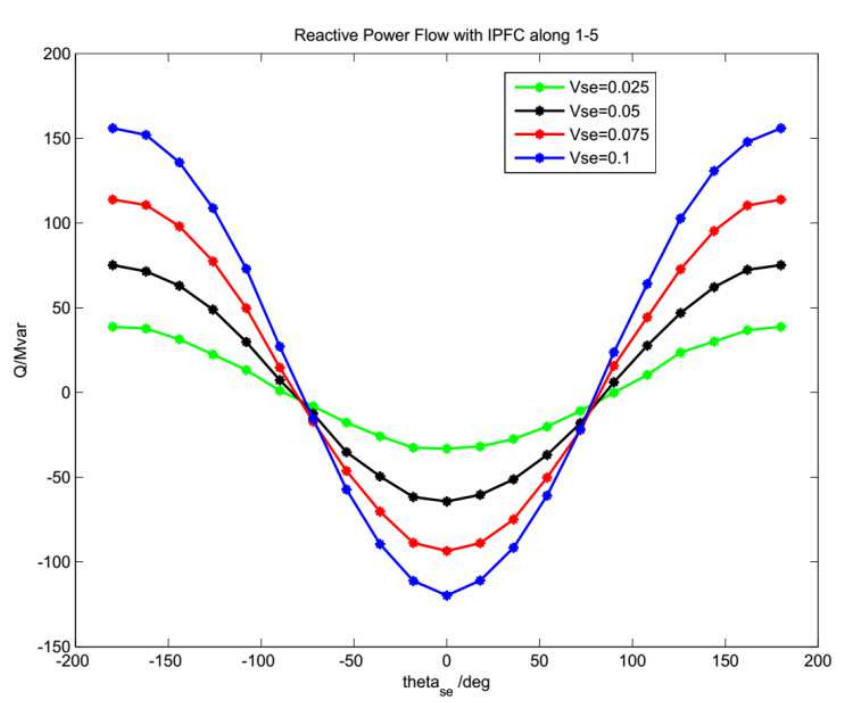

Figure 11. Reactive Power Flow with IPFC in the line connecting bus 1 to bus 5 at various values of $V$ se.

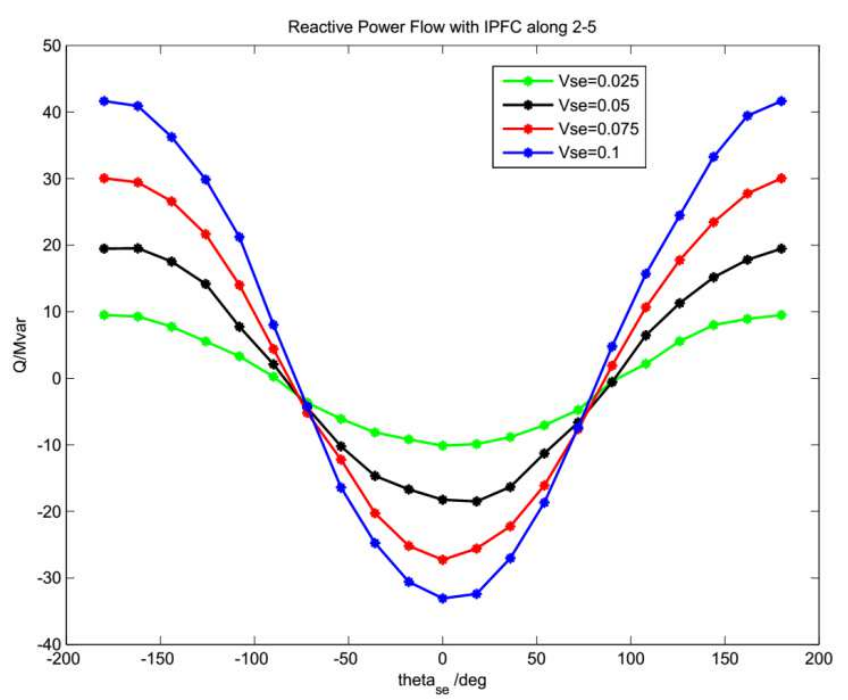

Figure 12. Reactive power flow with IPFC in the line connecting bus 2 to bus 5 at various values of $V$ se. 


\subsection{Test Case 2: 28 -Bus Power Flow Results Without and with IPFC}

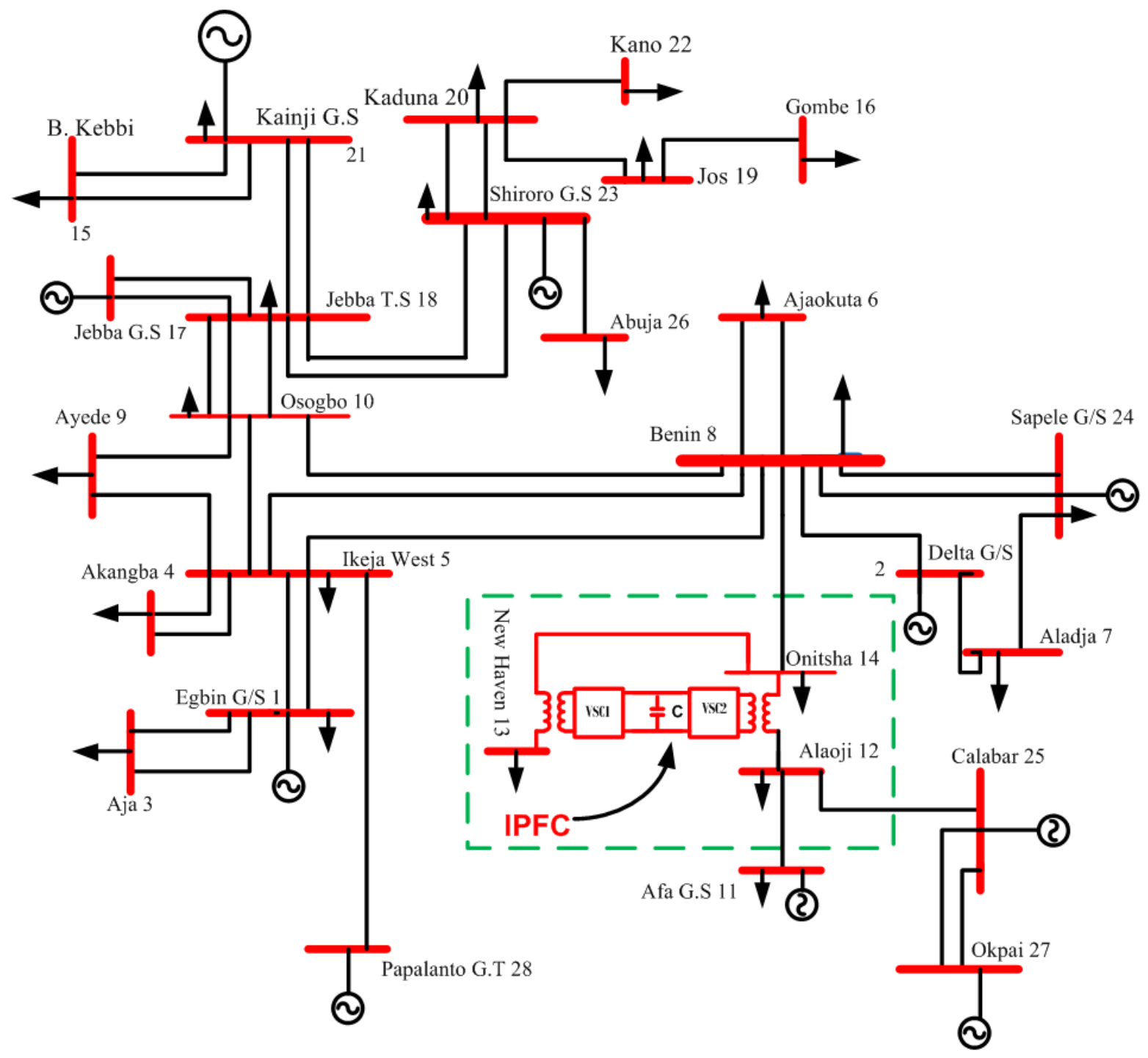

Figure 13. Nigerian 330kV, 28-Bus Power Network Grid with IPFC Installed.

Figure 13 depicts Nigerian 330kV, 28-Bus Power Network Grid with IPFC Installed. Figures 14 and 15 show the active and reactive power values without and with the incorporation of IPFC. Between the line connecting bus 12 and 14, Active power was $139.90 \mathrm{MW}$ without the incorporation of IPFC and 182.070 MW with IPFC (i.e active power increased by 42.17 MW. Reactive power was 48.300 MVar without IPFC and 28.166 MVar with IPFC (i.e reactive power reduced by 20.14 MVar having incorporated IPFC. Between the lines connecting bus 13 and 14, active power was $89.340 \mathrm{MW}$ without IPFC and $150.680 \mathrm{MW}$ with IPFC (i.e active power increased by $61.34 \mathrm{MW}$. Reactive power was $34.570 \mathrm{MVar}$ without IPFC and 46.470 MVar with IPFC (i.e reactive power increased by 11.09 Mvar.)

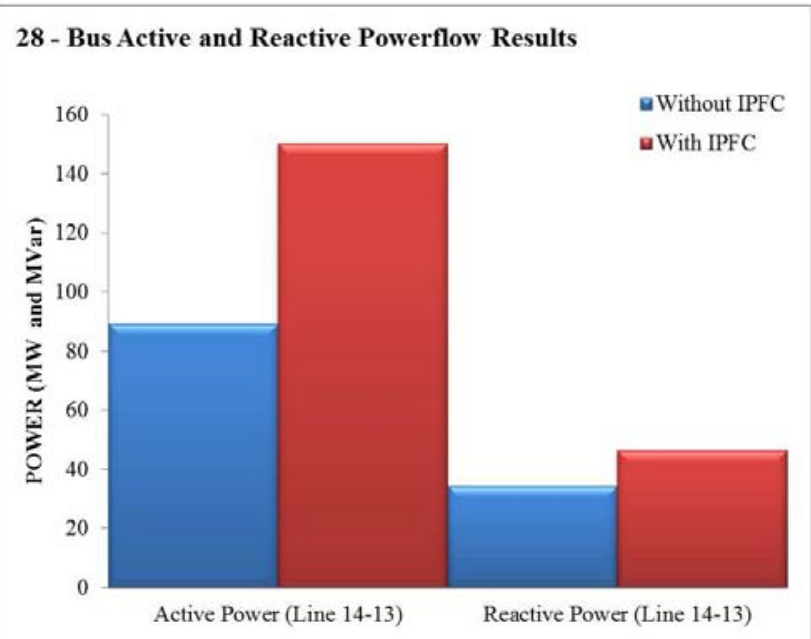

Figure 14. 28-Bus Active and Reactive Powerflow Results between the line connecting bus 14 to bus 13 . 
Table 3. Power Flow Result for 28 Bus System without the incorporation of IPFC.

\begin{tabular}{|c|c|c|c|c|c|}
\hline \multirow{2}{*}{$\begin{array}{l}\text { BUS } \\
\text { NUMBER }\end{array}$} & \multirow{2}{*}{$\begin{array}{l}\text { BUS } \\
\text { TYPE }\end{array}$} & \multicolumn{2}{|c|}{ LOAD } & \multicolumn{2}{|c|}{ GENERATOR } \\
\hline & & MW & MVar & MW & MVA \\
\hline 1 & Swing & 68.90 & 51.70 & 157.07 & 534.30 \\
\hline 2 & PV & 0.00 & 0.00 & 670.00 & -20.07 \\
\hline 3 & PQ & 274.40 & 205.80 & 0.00 & 0.00 \\
\hline 4 & $P Q$ & 344.70 & 258.50 & 0.00 & 0.00 \\
\hline 5 & PQ & 633.20 & 474.90 & 0.00 & 0.00 \\
\hline 6 & PQ & 13.80 & 10.30 & 0.00 & 0.00 \\
\hline 7 & PQ & 96.50 & 72.40 & 0.00 & 0.00 \\
\hline 8 & PQ & 383.30 & 287.50 & 0.00 & 0.00 \\
\hline 9 & PQ & 275.80 & 206.80 & 0.00 & 0.00 \\
\hline 10 & PQ & 201.20 & 150.90 & 0.00 & 0.00 \\
\hline 11 & PV & 52.50 & 39.40 & 431.00 & 317.53 \\
\hline 12 & PQ & 427.00 & 320.20 & 0.00 & 0.00 \\
\hline 13 & PQ & 177.90 & 133.40 & 0.00 & 0.00 \\
\hline 14 & PQ & 184.60 & 138.40 & 0.00 & 0.00 \\
\hline 15 & PQ & 114.50 & 85.90 & 0.00 & 0.00 \\
\hline 16 & PQ & 130.60 & 97.90 & 0.00 & 0.00 \\
\hline 17 & PQ & 11.00 & 8.20 & 0.00 & 0.00 \\
\hline 18 & PV & 0.00 & 0.00 & 495.00 & -101.20 \\
\hline 19 & PQ & 70.30 & 52.70 & 0.00 & 0.00 \\
\hline 20 & PQ & 193.00 & 144.70 & 0.00 & 0.00 \\
\hline 21 & PV & 7.00 & 5.20 & 624.70 & -267.22 \\
\hline 22 & PQ & 220.60 & 142.90 & 0.00 & 0.00 \\
\hline 23 & PV & 70.30 & 36.10 & 388.90 & 55.22 \\
\hline 24 & PV & 20.60 & 15.40 & 190.30 & 113.87 \\
\hline 25 & PQ & 110.00 & 89.00 & 0.00 & 0.00 \\
\hline 26 & PQ & 290.10 & 145.00 & 0.00 & 0.00 \\
\hline 27 & PV & 0.00 & 0.00 & 750.00 & -106.81 \\
\hline 28 & PV & 0.00 & 0.00 & 750.00 & 319.20 \\
\hline TOTAL & & 4371.8 & 3173.2 & 4456.98 & 844.842 \\
\hline
\end{tabular}

Figure 16 to Figure 19 shows the graphical behaviour of active power and reactive power at selected buses where IPFC has been installed (between the lines connecting buses 12-14 and $13-14$ ) while varying Vse and $\theta$ se control parameters. As Vse increases from $0.025 \mathrm{p} . \mathrm{u}$ at an interval of 0.025 to $0.1 \mathrm{p} . \mathrm{u}$ for different values of $\theta$ se (ranging from $-180^{\circ}$ to $+180^{\circ}$ ), the active power flow in both the lines increased appropriately and reactive power flow had expected response having incorporated IPFC

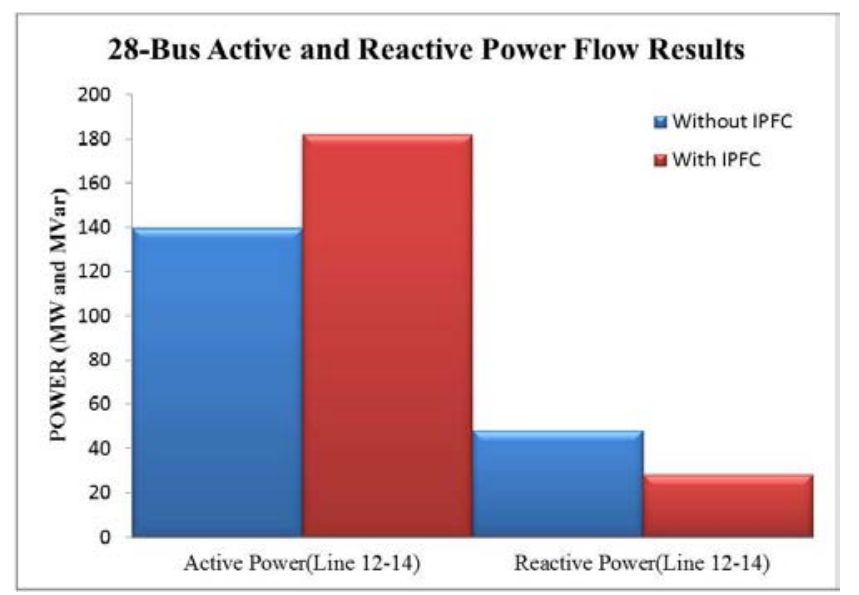

Figure 15. 28-Bus Active and Reactive Powerflow Results of the line connecting bus 12 to bus 14

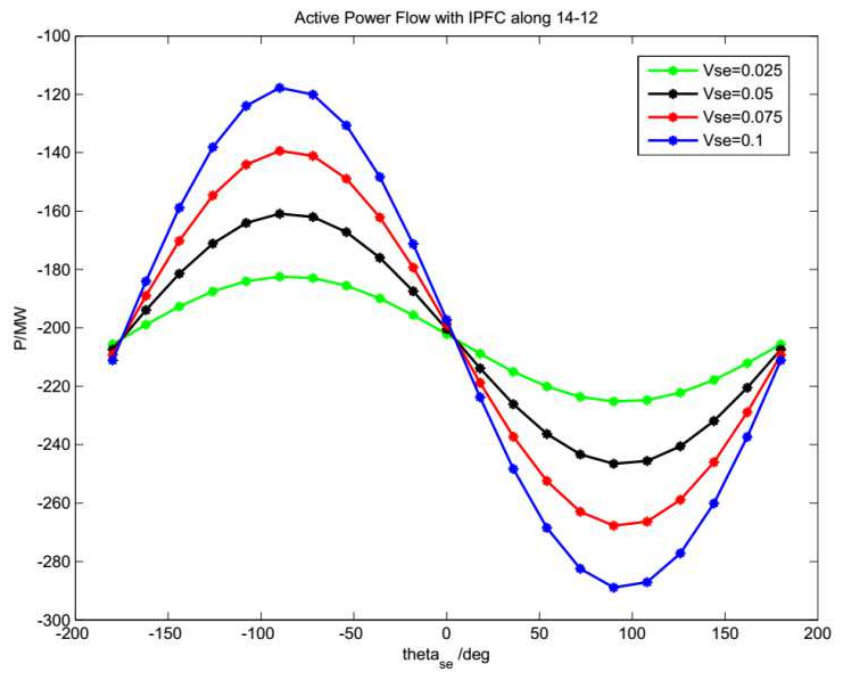

Figure 16. Active power flow with IPFC of the line connecting bus 14 to bus 12 at various values of $V$ se.

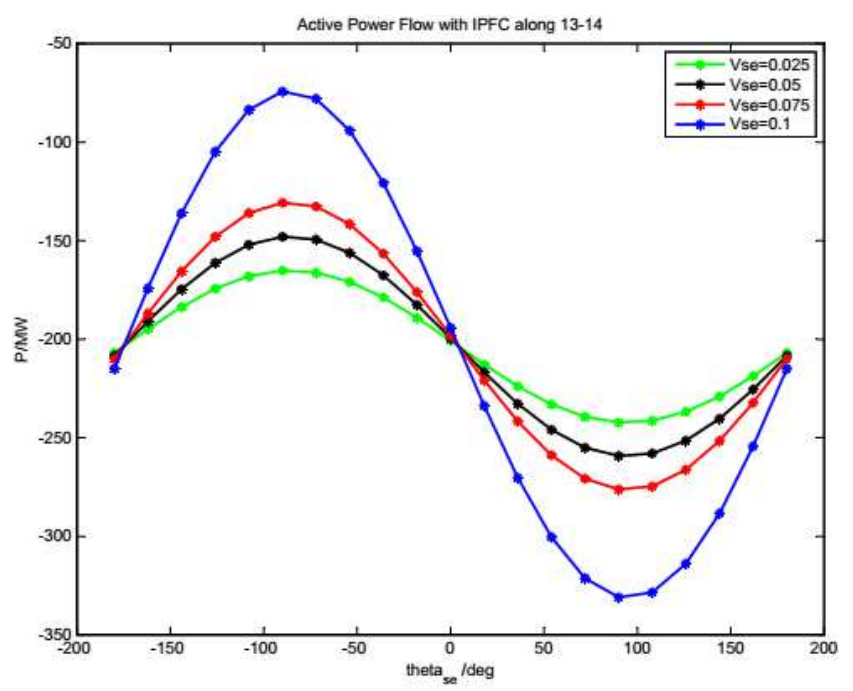

Figure 17. Active power flows with IPFC of the line connecting bus 13 to bus 14 at various values of $V$ se.

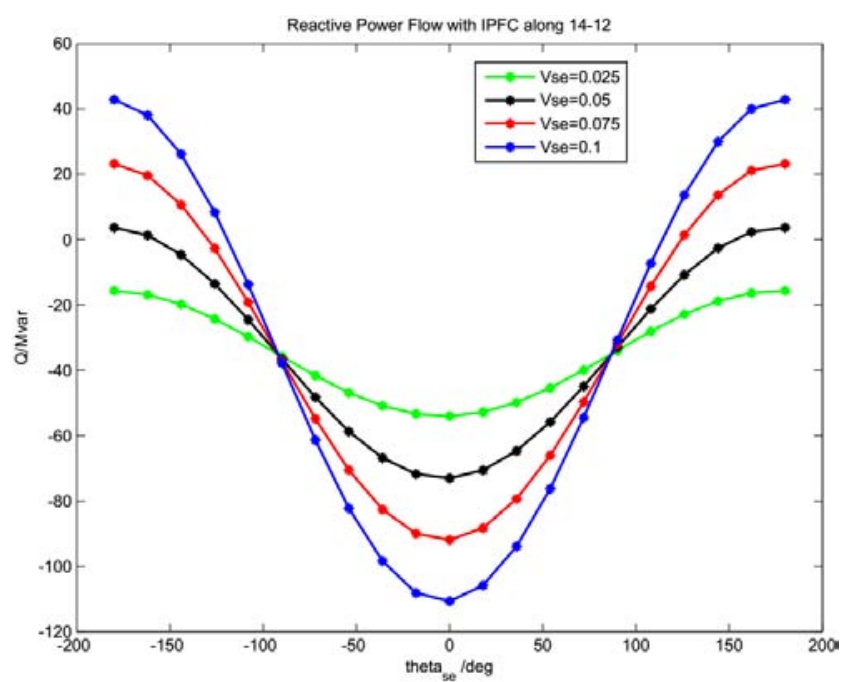

Figure 18. Reactive power flows with IPFC of the line connecting bus 12 to bus 14 at various values of Vse. 


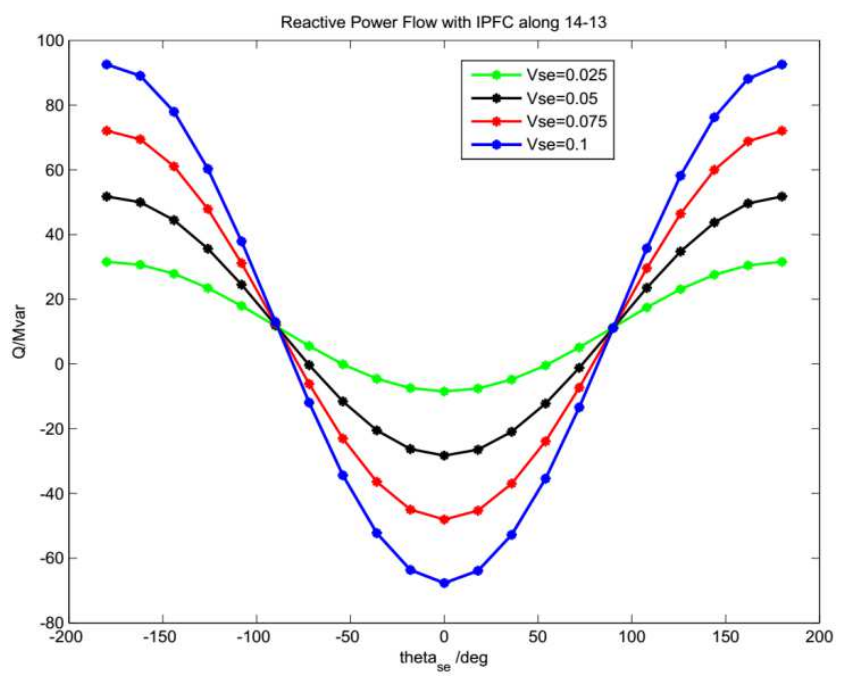

Figure 19. Reactive power flows with IPFC of the line connecting bus 13 to bus 14 at various values of Vse.

Table 4. 28-Bus and Line flows with IPFC at Series Voltage and Angle values of $V_{s e} \angle \theta_{s e}=0.085 \angle 105^{0}$

\begin{tabular}{llll}
\hline \multicolumn{4}{l}{ Active and Reactive Power Line Flows } \\
\hline Bus & \multicolumn{3}{l}{ With IPFC } \\
\hline From & To & MW & MVar \\
\hline 12 & 14 & 186.905 & 32.308 \\
13 & 14 & 148.539 & 16.711 \\
\hline
\end{tabular}

Table 4: Shows the active power and reactive power values when series voltage is 0.085 . There is an increase in the active and reactive power compared to the previously considered cases of the 28-Bus power system.

The application of IPFC into the Nigerian 28-bus power system has been used to control both active and reactive power flow while improving the overall voltage profile as shown in figure 20. The capacity of IPFC to provide compensation for different lines due to its two internal back-to-back, dc-to-dc converters connected to two transmission lines through the series coupling transformer and dc terminals of the converters connected via a common dc link has been demonstrated.

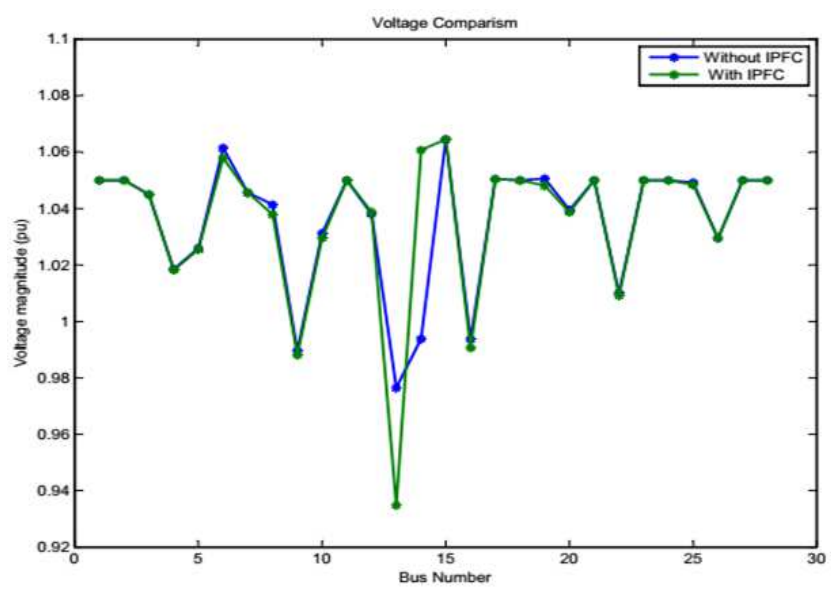

Figure 20. Voltage Comparison for 28-bus TCN without and with the incorporation of IPFC in Nigerian Power System.

Table 7 shows the maximum mismatch values for Newton-Raphson iteration and number of iterations for the two power systems considered. A smooth quadratic convergence characteristic of newton-Raphson method and an increased number of iteration with the installation of IPFC is observed. In both systems, IPFC has been used to improve active and reactive power, reduce the flow of heavily loaded lines in a more flexible way. The multiline control capacity of the device has also been demonstrated with the ability to provide control for more power system quantities simultaneously. Losses along transmission lines were reduced hence an enhanced performance for the power infrastructure. Power flow results have demonstrated the effectiveness and feasibility of the IPFC power injection model expressed in rectangular form. An increased bus voltage is also observed, and there is an improved multiline power flow control with minimized power losses.

Table 5. 28-Bus Active Power, Reactive Power, Active Power Loss and Reactive power loss Comparison without and with the incorporation of IPFC when Vse $=$ $0.075 \mathrm{~V}$ at $90^{\circ}$.

\begin{tabular}{|c|c|c|c|c|c|c|c|c|c|}
\hline \multicolumn{2}{|c|}{ BUS NUMBER } & \multicolumn{2}{|c|}{ ACTIVE POWER (MW) } & \multicolumn{2}{|c|}{$\begin{array}{l}\text { REACTIVE POWER } \\
\text { (MVAR) }\end{array}$} & \multicolumn{2}{|c|}{$\begin{array}{l}\text { ACTIVE POWER LOSS } \\
\text { (MW) }\end{array}$} & \multicolumn{2}{|c|}{$\begin{array}{l}\text { REACTIVE POWER LOSS } \\
\text { (MVAR) }\end{array}$} \\
\hline FROM & TO & $\begin{array}{l}\text { Without } \\
\text { IPFC }\end{array}$ & With IPFC & $\begin{array}{l}\text { Without } \\
\text { IPFC }\end{array}$ & With IPFC & $\begin{array}{l}\text { Without } \\
\text { IPFC }\end{array}$ & With IPFC & $\begin{array}{l}\text { Without } \\
\text { IPFC }\end{array}$ & With IPFC \\
\hline 1 & 3 & 137.360 & 137.360 & 97.580 & 97.580 & 0.160 & 0.160 & -5.320 & -5.320 \\
\hline 1 & 3 & 137.360 & 137.360 & 97.580 & 97.580 & 0.160 & 0.160 & -5.320 & -5.320 \\
\hline 2 & 8 & 331.600 & 331.180 & -23.730 & -11.160 & 4.290 & 3.430 & -14.330 & -11.360 \\
\hline 2 & 7 & 338.400 & 338.820 & 3.660 & 3.630 & 1.250 & 1.000 & -3.680 & -2.930 \\
\hline 5 & 4 & 172.660 & 172.660 & 124.480 & 124.490 & 0.310 & 0.310 & -4.770 & -4.760 \\
\hline 5 & 4 & 172.660 & 172.660 & 124.480 & 124.490 & 0.310 & 0.310 & -4.770 & -4.760 \\
\hline 5 & 1 & 93.960 & 89.050 & -163.750 & -165.580 & 0.690 & 0.690 & -20.040 & -20.080 \\
\hline 5 & 1 & 93.960 & 89.050 & -163.750 & -163.580 & 0.690 & 0.690 & -20.040 & -20.080 \\
\hline 7 & 24 & 240.660 & 241.070 & -65.060 & -65.110 & 1.380 & 1.110 & -16.860 & -13.460 \\
\hline 8 & 5 & 119.430 & 102.130 & -50.650 & -53.670 & 1.450 & 1.070 & -106.590 & -109.010 \\
\hline 8 & 5 & 119.430 & 102.130 & -50.650 & -53.670 & 1.450 & 1.070 & -106.590 & -109.010 \\
\hline 8 & 6 & 7.000 & 7.000 & -78.780 & -78.170 & 0.100 & 0.100 & -83.930 & -83.320 \\
\hline 8 & 14 & 128.340 & 194.330 & 78.550 & 146.270 & 1.400 & 2.750 & -45.280 & -22.470 \\
\hline 9 & 5 & 27.370 & 39.220 & -118.170 & -121.970 & 0.510 & 0.590 & -50.420 & -49.680 \\
\hline 10 & 5 & 160.960 & 173.640 & -57.440 & -59.230 & 2.410 & 2.820 & -86.560 & -83.280 \\
\hline 10 & 8 & 29.910 & 61.660 & -70.120 & -70.170 & 0.110 & 0.380 & -105.060 & -102.440 \\
\hline 10 & 9 & 307.600 & 319.780 & 75.970 & 74.800 & 4.430 & 4.760 & -12.670 & -10.030 \\
\hline
\end{tabular}




\begin{tabular}{|c|c|c|c|c|c|c|c|c|c|}
\hline \multicolumn{2}{|c|}{ BUS NUMBER } & \multicolumn{2}{|c|}{ ACTIVE POWER (MW) } & \multicolumn{2}{|c|}{$\begin{array}{l}\text { REACTIVE POWER } \\
\text { (MVAR) }\end{array}$} & \multicolumn{2}{|c|}{$\begin{array}{l}\text { ACTIVE POWER LOSS } \\
\text { (MW) }\end{array}$} & \multicolumn{2}{|c|}{$\begin{array}{l}\text { REACTIVE POWER LOSS } \\
\text { (MVAR) }\end{array}$} \\
\hline FROM & TO & $\begin{array}{l}\text { Without } \\
\text { IPFC }\end{array}$ & With IPFC & $\begin{array}{l}\text { Without } \\
\text { IPFC }\end{array}$ & With IPFC & $\begin{array}{l}\text { Without } \\
\text { IPFC }\end{array}$ & With IPFC & $\begin{array}{l}\text { Without } \\
\text { IPFC }\end{array}$ & With IPFC \\
\hline 11 & 12 & 189.250 & 189.250 & 139.070 & 126.030 & 0.510 & 0.390 & -6.900 & -5.720 \\
\hline 11 & 12 & 189.250 & 189.250 & 139.070 & 126.030 & 0.510 & 0.390 & -6.900 & -5.720 \\
\hline 12 & 14 & 139.900 & 182.070 & 48.300 & 28.160 & 3.570 & 0.000 & -35.410 & 25.150 \\
\hline 14 & 13 & 89.340 & 30.160 & 34.570 & -84.370 & 0.390 & 0.210 & -32.130 & -32.420 \\
\hline 13 & 14 & 89.340 & 150.680 & 46.470 & 34.570 & 0.390 & 1.160 & -32.130 & -23.700 \\
\hline 17 & 10 & 236.340 & 255.750 & -9.720 & -6.540 & 3.120 & 3.660 & -42.820 & -38.640 \\
\hline 17 & 10 & 236.340 & 255.750 & -9.720 & -6.540 & 3.120 & 3.660 & -42.820 & -38.640 \\
\hline 17 & 10 & 236.340 & 255.750 & -9.720 & -6.540 & 3.120 & 3.660 & -42.820 & -38.640 \\
\hline 17 & 23 & 136.690 & 107.580 & 107.820 & -64.130 & 1.640 & 0.810 & -93.440 & -78.480 \\
\hline 17 & 23 & 136.690 & 107.580 & 107.820 & -64.130 & 1.640 & 0.810 & -93.440 & -78.480 \\
\hline 18 & 17 & 247.500 & 247.500 & 247.500 & -50.600 & 0.120 & 0.110 & -1.010 & -1.020 \\
\hline 18 & 17 & 247.500 & 247.500 & 247.500 & -50.600 & 0.120 & 0.110 & -1.010 & -1.020 \\
\hline 19 & 16 & 132.830 & 132.840 & 132.840 & -8.590 & 2.230 & 2.240 & -106.490 & -105.750 \\
\hline 19 & 20 & 121.590 & 179.360 & 178.880 & -37.600 & 1.090 & 1.900 & -80.200 & -56.230 \\
\hline 20 & 22 & 111.430 & 111.430 & 111.430 & -14.900 & 1.130 & 0.910 & -86.350 & -68.930 \\
\hline 20 & 22 & 111.430 & 111.430 & 111.430 & -14.900 & 1.130 & 0.910 & -86.350 & -68.930 \\
\hline
\end{tabular}

Table 6. Continuation, 28-Bus Active power, Reactive power, Active power loss and Reactive power loss Comparison without and with the incorporation of IPFC.

\begin{tabular}{|c|c|c|c|c|c|c|c|c|c|}
\hline \multicolumn{2}{|c|}{ BUS NUMBER } & \multicolumn{2}{|c|}{ ACTIVE POWER (MW) } & \multicolumn{2}{|c|}{$\begin{array}{l}\text { REACTIVE POWER } \\
\text { (MVar) }\end{array}$} & \multicolumn{2}{|c|}{$\begin{array}{l}\text { ACTIVE POWER LOSS } \\
\text { (MW) }\end{array}$} & \multicolumn{2}{|c|}{$\begin{array}{l}\text { REACTIVE POWER LOSS } \\
\text { (MVAR) }\end{array}$} \\
\hline FROM & TO & Without IPFC & $\begin{array}{l}\text { With } \\
\text { IPFC }\end{array}$ & Without IPFC & $\begin{array}{l}\text { With } \\
\text { IPFC }\end{array}$ & $\begin{array}{l}\text { Without } \\
\text { IPFC }\end{array}$ & With IPFC & $\begin{array}{l}\text { Without } \\
\text { IPFC }\end{array}$ & With IPFC \\
\hline 21 & 15 & 57.680 & 57.680 & 57.680 & -89.990 & 0.430 & 0.430 & -132.940 & -132.940 \\
\hline 21 & 15 & 57.680 & 57.680 & -89.990 & -89.990 & 0.430 & 0.430 & -132.940 & -132.940 \\
\hline 21 & 17 & 251.170 & 251.170 & -46.220 & -45.750 & 1.860 & 1.850 & -21.200 & -21.200 \\
\hline 21 & 17 & 251.170 & 251.170 & -46.220 & -45.750 & 1.860 & 1.850 & -21.200 & 21.200 \\
\hline 23 & 20 & 148.450 & 119.960 & 0.770 & 6.640 & 0.780 & 0.520 & -35.380 & -37.240 \\
\hline 23 & 26 & 145.900 & 145.900 & 38.100 & 38.100 & 0.850 & 0.680 & -34.400 & -27.520 \\
\hline 23 & 26 & 145.900 & 145.900 & 38.100 & 38.100 & 0.850 & 0.680 & -34.400 & -27.520 \\
\hline 24 & 8 & 204.490 & 204.690 & 25.140 & 52.150 & 0.780 & 0.830 & -15.690 & -15.240 \\
\hline 24 & 8 & 204.490 & 204.690 & 25.140 & 52.150 & 0.780 & 0.830 & -15.690 & -15.240 \\
\hline 25 & 12 & 146.100 & 116.890 & -34.160 & -35.200 & 1.380 & 0.880 & -72.440 & -76.200 \\
\hline 25 & 12 & 146.100 & 116.650 & -34.160 & -35.200 & 1.380 & 0.880 & -72.440 & -76.200 \\
\hline 27 & 25 & 375.000 & 375.000 & -53.410 & -52.220 & 10.080 & 10.800 & -10.490 & -10.450 \\
\hline 27 & 25 & 375.000 & 375.000 & -53.410 & -52.220 & 10.800 & 10.800 & -10.490 & -10.450 \\
\hline 28 & 5 & 375.000 & 375.000 & 159.600 & 163.340 & 2.460 & 2.480 & -1.950 & -1.800 \\
\hline 28 & 5 & 375.000 & 375.000 & 159.600 & 163.340 & 2.460 & 2.480 & -1.950 & -1.800 \\
\hline \multicolumn{2}{|l|}{ TOTAL } & 9005.64 & 9141.86 & 1424.57 & -296.12 & 85.81 & 83.31 & -2244.45 & -1981.46 \\
\hline
\end{tabular}

Table 7. Performance Calculation for Newton Raphson iteration without and with IPFC.

\begin{tabular}{lllll}
\hline \multirow{2}{*}{ Power System } & \multicolumn{2}{l}{ Iteration Number } & \multicolumn{2}{l}{ Maximum Mismatch } \\
\cline { 2 - 5 } & Without & With & Without & With \\
\hline IEEE-14 Bus & 4 & 9 & $1.2856 \mathrm{e}-14$ & $1.9901 \mathrm{e}-14$ \\
TCN-28 Bus & 6 & 7 & $1.2004 \mathrm{e}-13$ & $1.9629 \mathrm{e}-13$ \\
\hline
\end{tabular}

\section{Conclusion}

The primary function of the transmission system is to transport bulk power from sources of desirable generation to distribution delivery points. Hitherto, inadequate active power, reactive power and voltage profile has been recorded at the receiving end due to losses on the transmission lines. However, this research work has investigated the application of IPFC rectangular model to longitudinal systems (Nigerian $330 \mathrm{kV}$ transmission system) as the major case study for its steady state operation enhancement. Simulations were performed on both the standard IEEE 14-bus system (for result performance comparison standardization purpose), and TCN Nigerian 28-Bus system. The simulation was achieved by a script program written MATLAB 8.1.0.604 (version R2013b) and the power flow results were presented without and with the incorporation of IPFC. The incorporation of the IPFC into the Nigerian transmission network (which conforms with the results of incorporating IPFC into IEEE 14-bus for similar steady-state control enhancement, active and reactive power improvement purpose) has demonstrated technical benefits that complement the transmission system performance through minimized power losses, better active and reactive 
power values, better voltage profile within the binding limit. Hence, minimized transmission losses and an improved electrical energy delivered to the end users.

\section{References}

[1] Zhang, X. P; Rehtanz, C.; Pal B. (2012), "Flexible AC Transmission System: Modelling and Control", Springer-Verlag Berlin Heidelberg New York Dordrecht London, ISSN 1612-1287.

[2] Sanusi Ohiare. (2015), "Expanding Electricity Access to all Nigerians: A spatial planning and cost analysis", A Springer open access journal of Energy, Sustainability and Society.

[3] Muraliu, D.; Rajaram, M.;, Reka; N. (2010), "Comparison of FACTS Devices for Power System Stability Enhancement", International Journal of Computer Applications (0975 - 8887), Volume 8- No. 4.

[4] Abido, M. A (2009), "Power System Stability Enhancement using Facts Controllers: A Review", The Arabian Journal for Science and Engineering, Volume 34, Number 1B, pp. 12-30.

[5] Natália, M. R.; Santos; Dias, P. O; Fernão, P V; (2011), 'Use of an Interline Power Flow Controller Model for Power Flow Analysis' SciVerse, Science Direct International Conference on Advances in Energy Engineering (ICAEE2011), ELSIVIER, pp $2096-2101$.

[6] Kamel, S.; and Jurado, F.; (2013), "Power flow analysis with easy modeling of interline power flow controller", ELSIVIER, Electric Power Systems Research 108, pp 234-244.

[7] Naresh, B. A. V.; Sivanagaraju; Padmanabharaju, Ch.; and Ramana, T; (2010), 'Multi-Line Power Flow Control using Interline Power Flow Controller (IPFC) in Power Transmission Systems', World Academy of Science, Engineering and Technology 39.

[8] Duncan, M. S.; and Thomas, O; (2012), "Power System Analysis and Design", Global Engineering Publisher for Cengage Learning, Fifth Edition, and ISBN: 13: 978-1-111-42577-7.

[9] Bindeshwar, S; Verma, K. S.; Pooja, M.; Rashi M.; Utkarsha, S.; and Aanchal, B; (2012), "Introduction to FACTS Controllers: A Technological Literature Survey", International Journal of Automation and Power Engineering Volume 1 Issue 9.

[10] Lutful K. S. M.; Hasib C. A.; Mosaddequr R.; Jahangir A.; (2014), 'Inclusion of Slack Bus in Newton Raphson Load Flow
Study', 8th International Conference on Electrical and Computer Engineering Dhaka, Bangladesh, Volume 7, Number 14 pp 282-285.

[11] Hbti, K. U. P.; BIET, J. U. P; (2012), 'Introduction To Facts Controllers A Critical Review', International Journal of Reviews in Computing, ISSN: 2076-3328, volume 8 number 3.

[12] Adepoju, G. A.; Komolafe, O. A.; and Aborisade, D. O.; (2011). Power Flow Analysis of the Nigerian Transmission System Incorporating FACTS controllers. International Journal of Applied Science and Technology. 1 (5).

[13] PHCN Transmission Company Nigeria (TCN) Oshogbo (2015), Generation and Transmission Grid 330kV Management and Control Centre.

[14] Sreejith S.; Sishaj P. S.; Selvan M. P; (2013), “Optimal location of interline power flow controller in a power system network using $\mathrm{ABC}$ algorithm. Archives of Electrical Engineering. Volume 1, Issue 62, pp. 91-110.

[15] Amir, G.; Seyed, Y. E.; and Morteza, G.; (2017), “Active power based distance protection scheme in the presence of series compensators", Protection and Control of Modern Power Systems, DOI 10.1186/s41601-017-0034-4.

[16] Rakhmad, S. L.; (2012), "Digital Simulation of the Generalized Unified Power Flow Controller System with 60-Pulse GTO-Based Voltage Source Converter", International Journal of Energy Engineering, 2012.

[17] Rakhmad, S. L; Sasongko, P. H.; and Tumiran; (2012), "Selection of Suitable Location of the FACTS Devices for Optimal Power Flow", International Journal of Electrical \& Computer Sciences IJECS-IJENS Vol: 12 No: 03.

[18] Radha, G.; Gopalakrishnan, V.; (2013), “Application of An Interline Power Flow Controller as AGC " Journal of Theoretical and Applied Information Technology Vol. 54 No. 3 ISSN: 1992-8645.

[19] Manoj, A.; and Sachin, T.; (2016), "Performances Analysis Of Interline Power Flow Controller", International Journal Of Innovative Engineering Research, Vol 3, Issue 5, (E-Issn: 2349-882x).

[20] Dhurvey, S. N.; and Chandrakar, V. K.; (2016), "Improvement of Power System Performance Using Fuzzy Logic Based Interline Power Flow Controller [IPFC]", Journal of Power and Energy Engineering, Vol 4, 67-77.

[21] National Power Training Institute of Nigeria (NAPTIN) "https://www.naptinportal.com.ng". 